\title{
Macrophages commit postnatal endothelium-derived progenitors to angiogenesis and restrict endothelial to mesenchymal transition during muscle regeneration
}

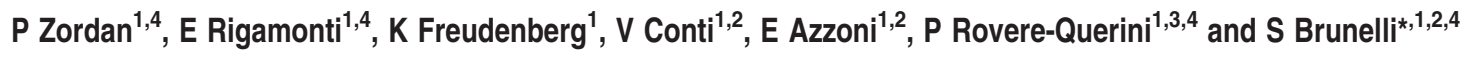

The damage of the skeletal muscle prompts a complex and coordinated response that involves the interactions of many different cell populations and promotes inflammation, vascular remodeling and finally muscle regeneration. Muscle disorders exist in which the irreversible loss of tissue integrity and function is linked to defective neo-angiogenesis with persistence of tissue necrosis and inflammation. Here we show that macrophages (MPs) are necessary for efficient vascular remodeling in the injured muscle. In particular, MPs sustain the differentiation of endothelial-derived progenitors to contribute to neo-capillary formation, by secreting pro-angiogenic growth factors. When phagocyte infiltration is compromised endothelial-derived progenitors undergo a significant endothelial to mesenchymal transition (EndoMT), possibly triggered by the activation of transforming growth factor- $\beta /$ bone morphogenetic protein signaling, collagen accumulates and the muscle is replaced by fibrotic tissue. Our findings provide new insights in EndoMT in the adult skeletal muscle, and suggest that endothelial cells in the skeletal muscle may represent a new target for therapeutic intervention in fibrotic diseases.

Cell Death and Disease (2014) 5, e1031; doi:10.1038/cddis.2013.558; published online 30 January 2014

Subject Category: Immunity

The homeostatic response of skeletal muscle to injury involves various cell populations. After acute injury, the initial phase of muscle repair is characterized by necrosis of the tissue and activation of an inflammatory response. ${ }^{1,2}$ Growth factors and inflammatory cytokines released by infiltrating leukocytes lead to the activation of cells, which have the capacity to reconstitute the damaged muscle and promote re-vascularization of the tissue.

Progenitors in the muscle comprise the satellite cells, which are the primary myogenic stem cells responsible for skeletal muscle regeneration after damage, ${ }^{3}$ and vessel-associated progenitors. ${ }^{4}$ Vascular progenitors contribute to muscle regeneration by induction of new vessels, therefore increasing tissue perfusion and oxygenation, and through differentiation in muscle fibers. ${ }^{5}$ Angiogenesis and myogenesis take place simultaneously during muscle regeneration: endothelial cells control both myogenic cell growth and quiescence. Conversely, myogenic cells increase angiogenesis. ${ }^{6-8}$

Macrophages (MPs) are the major infiltrating population in injured muscle. Their functions during muscle regeneration and the mechanisms and the molecules involved have been only partially elucidated. At least two distinct MP populations exist. Classically activated inflammatory MPs express high levels of molecules involved in T-cell activation and costimulation while alternatively activated MPs express high levels of scavenger receptors. ${ }^{9-12}$ The phagocytosis of muscle debris modulates the response of muscle to acute injury, promoting the switch of classically activated toward alternatively activated MPs, an event that contributes to myogenesis ${ }^{13}$ and might have a role in the recruitment and differentiation of vascular-associated progenitors. ${ }^{14,15}$

Vessels failing to assemble and a jeopardized angiogenesis concur to muscle wasting; ${ }^{7,16}$ these might depend on a primitive defect of endothelial progenitors or on defective signaling necessary for their survival, proliferation or differentiation. The loss of endothelial identity in favor of a mesenchymal phenotype can also lead to tissue disorganization and fibrosis. ${ }^{17}$ This phenomenon, referred to as endothelial to mesenchymal transition (EndoMT), has been proposed to exacerbate the severity of many different diseases, still has not been described in the skeletal muscle.

\footnotetext{
${ }^{1}$ Division of Regenerative Medicine, Stem Cells and Gene Therapy, San Raffaele Scientific Institute, Milano, Italy; ${ }^{2}$ Department of Health Sciences, University of MilanoBicocca, San Raffaele Scientific Institute, Milano, Italy and ${ }^{3}$ San Raffaele University, Milano, Italy

*Corresponding author: S Brunelli, Department of Health Sciences, University of Milano-Bicocca San Raffaele Scientific Institute, via Cadore 48, 20900 Monza, Italy or Division of Regenerative Medicine, Stem Cells and Gene Therapy via Olgettina 58, Milano 20132, Italy. Tel: +39 0226435066; Fax: +39 0226434621; E-mail: brunelli.silvia@hsr.it

${ }^{4}$ These authors contributed equally to this work.

Keywords: macrophages; endothelial progenitors; VE-cadherin; EndoMT

Abbreviations: Ang, angiopoietin; $\beta$-Gal, $\beta$-galactosidase; BMP, bone morphogenetic protein; Cll, clodronate; Cre, Cre recombinase; CTX, cardiotoxin; ECM, extracellular matrix; EMT, epithelial to mesenchymal transition; EYFP, enhanced yellow fluorescent protein; FACS, fluorescence-activated cell sorting; FAP, fibroadipogenic progenitor; IF, immunofluorescence; IHC, immunohistochemistry; IL, Interleukin; HIF- $\alpha$, hypoxia-inducible factor alpha; PDGF, platelet-derived growth factor; PFA, paraformaldehyde; MMP, metalloprotease; MP, macrophage; NG2, neural/glial antigen 2; qPCR, quantitative real-time PCR; SMA, smooth muscle actin; TA, tibialis anterior; TAM, tamoxifen; TGF- $\beta$, transforming growth factor- $\beta$; TUNEL, terminal deoxynucleotidyl transferase dUTP nick end labeling; Ve-Cad, Ve-Cadherin; VEGF, vascular endothelial growth factor

Received 02.9.13; revised 13.12.13; accepted 13.12.13; Edited by G Melino
} 
Here we have investigated the fate of postnatal endothelial progenitors using a transgenic lineage-tracing approach and verified that MP infiltration is necessary for the differentiation of endothelial-derived progenitors, while inhibiting EndoMT and subsequent fibrosis.

\section{Results}

Postnatal VE-Cadherin + derived cells differentiate to endothelial cells in growing and adult skeletal muscle. We have investigated angiogenesis and the fate of postnatal endothelial progenitors in the adult skeletal muscle, by taking advantage of transgenic mice expressing a tamoxifen (TAM)-inducible form of Cre recombinase (CRE-ER ${ }^{T 2}$ ) under the control of the endothelial-specific gene VE-Cadherin (VE-Cad) regulatory sequences, Cdh5-CreER ${ }^{\mathrm{T} 2} \cdot{ }^{18}$ These mice were crossed with the reporter mice R26R-enhanced yellow fluorescent protein (EYFP) ${ }^{19}$ or R26R-NZG ${ }^{20}$ and Cre recombination was induced in double transgenic mice by TAM injection at stages P6-P7-P8, thus labeling postnatal VE-cadherin-expressing cells.

To verify the specificity of labeling, tibialis anterior (TA), quadriceps or triceps muscles were retrieved immediately after the induction ( $72 \mathrm{~h}$ ) or in adult mice (60 days). At both times, the majority of EYFP ${ }^{+}$or $\beta$-galactosidase ${ }^{+}\left(\beta\right.$-Gal $\left.{ }^{+}\right)$ cells expressed the endothelial marker CD31 (100\% at $72 \mathrm{~h}$, $93 \% \pm 6.6$ at P60; Figure 1a, Supplementary Figure S1). Only rare cells co-expressed $\alpha$-smooth muscle actin (SMA) or neural/glial antigen 2 (NG2) markers of mesenchymal cells, such as smooth muscle and pericytes ( $<4 \pm 2.4 \%$ at P60). Consistently, EYFP ${ }^{+}$cells isolated by fluorescence-activated cell sorting (FACS) from muscles of Cdh5-CreER ${ }^{\mathrm{T} 2}$;R26REYFP mice, $72 \mathrm{~h}$ and 60 days after TAM injection (Figure $1 \mathrm{~b}$ ), mainly expressed endothelial transcripts (VE-Cad and CD31), even if expression of mesenchymal genes (in particular $\alpha$-SMA and a lower extent c/EBP, PDGFR- $\beta$ ) and of some hematopoietic-specific transcripts (CD45, CD90) was detectable (Figure 1c). This suggests potency for mesenchymal differentiation. No myogenic-specific transcripts were expressed. These results indicate that the postnatal endothelial progenitors primarily differentiate into endothelial cells in the muscle.

\section{Capillary network formation upon muscle damage parallels the modulation of MP-specific angiogenic and matrix remodeling factors. To investigate angiogen- esis and the fate of endothelial progenitors during muscle regeneration, we elicited an acute sterile damage in 2 months old Cdh5-CreER ${ }^{\text {T2 }}$;R26R-EYFP or R26R-NZG (after postnatal Cre induction) by injecting cardiotoxin (CTX) in the TA, quadriceps or triceps muscles. Injured}

and uninjured muscles were collected 1, 3, 5, 7, 10 and 15 days after injury.

We analyzed vessel organization by CD31 immunofluorescence (IF) on TA muscles sections. Three days after damage, terminal deoxynucleotidyl transferase dUTP nick end labeling (TUNEL) assay showed massive death of $\mathrm{CD} 31^{+}$cells (Supplementary Figure S3). Two days later, we observed the presence of single $\mathrm{CD} 31^{+}$cells not assembled anymore in capillary vessels. Reorganization in vessels started soon after and was completed by day 15 (Figure 2a). At all times, $\mathrm{EYFP}^{+}$or $\beta$-Gal ${ }^{+}$endothelial-derived progenitors co-expressed at high frequency the endothelial marker CD31, demonstrating that they contribute to the revascularization of the tissue (Figure 2a, Supplementary Figure S1).

Vessel remodeling was accompanied by the modulation of the expression of specific cytokines and angiogenic factors, as assessed by quantitative real-time PCR (qPCR) analysis or western blot on total muscle lysates (Figure 2b). As a consequence of hypoxia, levels of angiopoietin II (Ang-II) and hypoxia-inducible factor 1 alpha (HIF-1 $\alpha$ ) increased immediately after damage, at RNA and protein levels. Ang-II may contribute to trigger angiogenesis soon after in conjunction with vascular endothelial growth factor- $\beta$ (VEGF- $\beta$ ). Transforming growth factor- $\beta$ (TGF- $\beta$ ), platelet-derived growth factor- $\alpha$ (PDGF- $\alpha$ ) and $\beta$ also peaked soon after damage. The drop in expression of VEGF- $\beta$ and Ang-I immediately after injury is possibly due to death of endothelial cells and the disassembly of the capillary network. Expression of metalloproteases (MMPs) was also modulated. MMP2, MMP13 and MMP14 levels increased 3 days after damage and persisted till day 15; remodeling and maintenance of the extracellular matrix (ECM) is indeed required for effective tissue healing (Figure $2 b$ ).

To investigate the role of infiltrating MPs recruited at the site of damage as a source of molecules responsible for the vascular and matrix remodeling, we isolated CD11b ${ }^{+} \mathrm{MPs}$ from the muscle 1, 3, 5, 7 and 10 days after CTX injection and performed qPCR and/or western blot analysis. Circulating $\mathrm{CD}_{11 \mathrm{~b}^{+}}$cells from untreated mice were used as positive control. HIF- $1 \alpha$ accumulated immediately after injury both at mRNA and protein levels (Figure 2c). Consistently, MP expression of angiogenic factors, such as PDGF- $\alpha$ and $\beta$ and VEGF increased during regeneration. TGF- $\beta$ was persistently expressed throughout tissue remodeling (Figure 2c). Ang-Il expression was bimodal, with peaks immediately and 10 days after damage. Ang-I was consistently limited. Infiltrating $\mathrm{CD}_{11} \mathrm{~b}^{+}$cells highly expressed MMP13 and MMP14 soon after damage and throughout the healing process. MMP2 was expressed by MPs during the late phases of muscle regeneration with a peak around day 10 ,

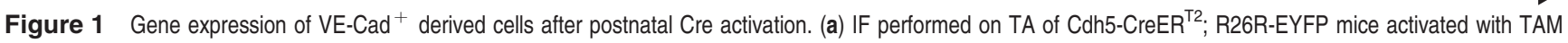
injection at postnatal days (P) 6-8, at P11 and P60. Representative images of muscle cross-sections immunostained with antibodies specific for CD31 (in red), EYFP (in green), showing colocalization of labeled cells with CD31. Magnification $\times 20$. Scale bar: $50 \mu \mathrm{m}$. (b) Gating strategy for FACS sorting of EYFP ${ }^{+}$cells from muscle; $2 \mathrm{D}$ density plot showing FS versus SS, delimits a tight region around the live cell population (R1). A second density plot, gated only on events encircled within R1, shows $\mathrm{EYFP}^{+}$cells on the $\mathrm{x}$-axis and SS on the $y$ axis (R2). EYFP ${ }^{+}$cells are selected and sorted. Cells are used for RNA extraction, at P11 and P60. (c) Real-time PCR performed on cDNA obtained from RNA of EYFP ${ }^{+}$cells sorted from P11 and P60 Cdh5-CreER ${ }^{\text {T2 }}$, R26R-EYFP mice activated with TAM injection at postnatal days (P) 6-8. The data are normalized on cyclophillin A expression
} 
consistently with the proposed involvement of MMP2 in the degradation of collagen IV of the basement membrane during myoblast proliferation, migration and fusion. ${ }^{21}$
As previously reported, we confirmed that cytokines expression was modulated during the response to injury. Interleukin-10 (IL-10) peaked at day 3 after injury and its

a
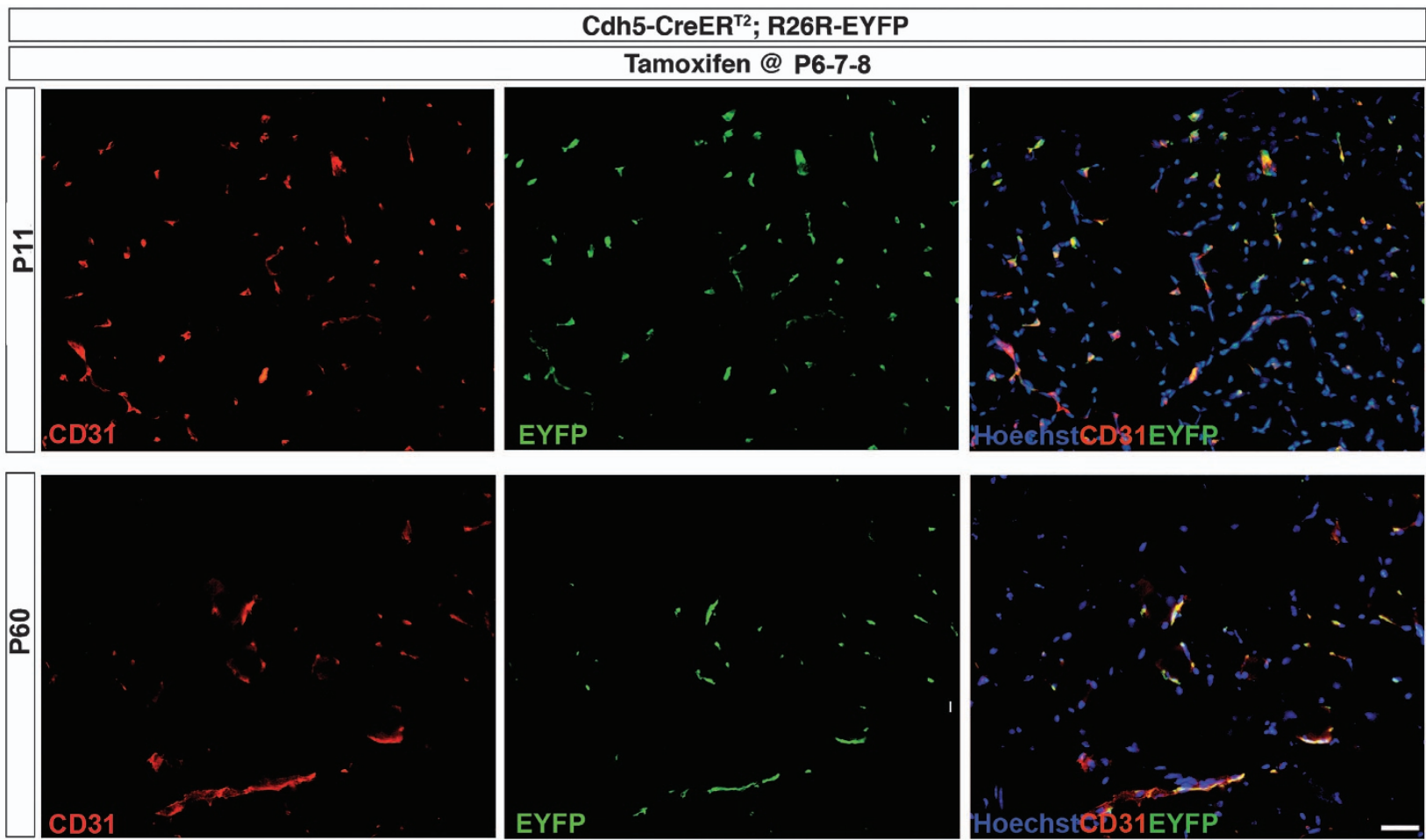

b
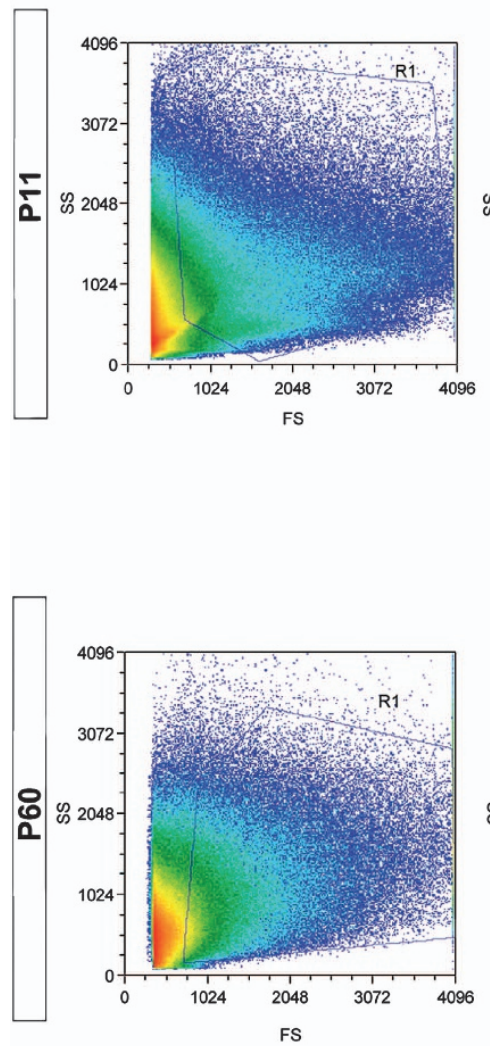

C

mRNA expression/cyclophillin A
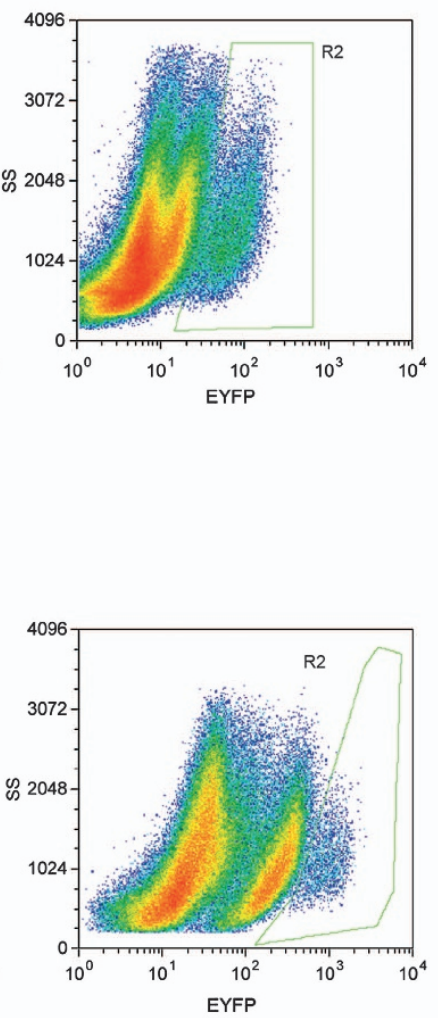

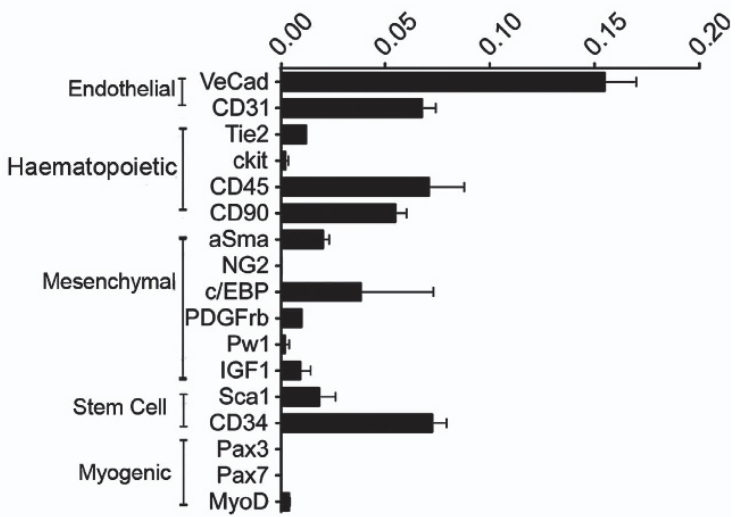

mRNA expression/cyclophillin A

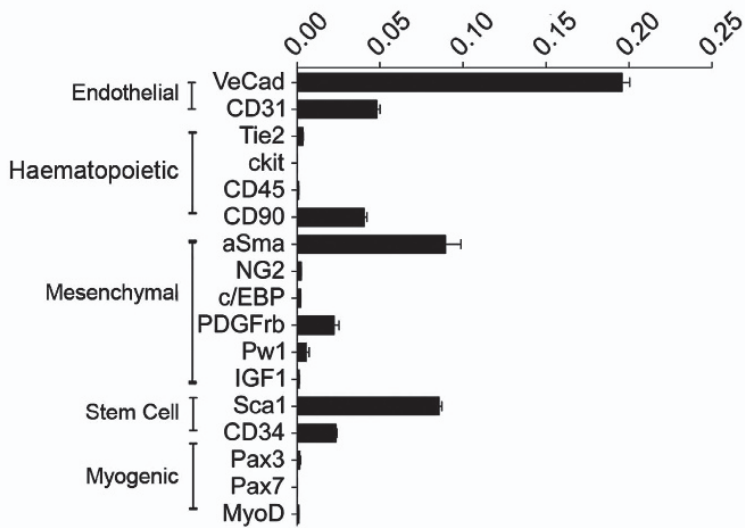




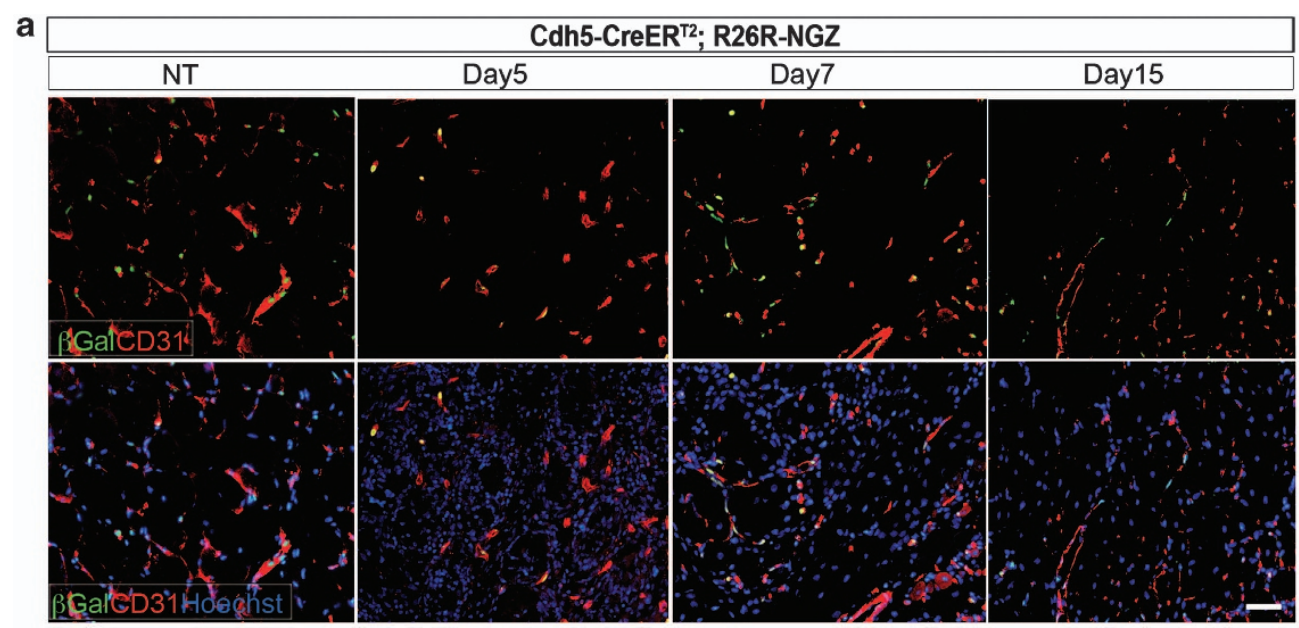

b
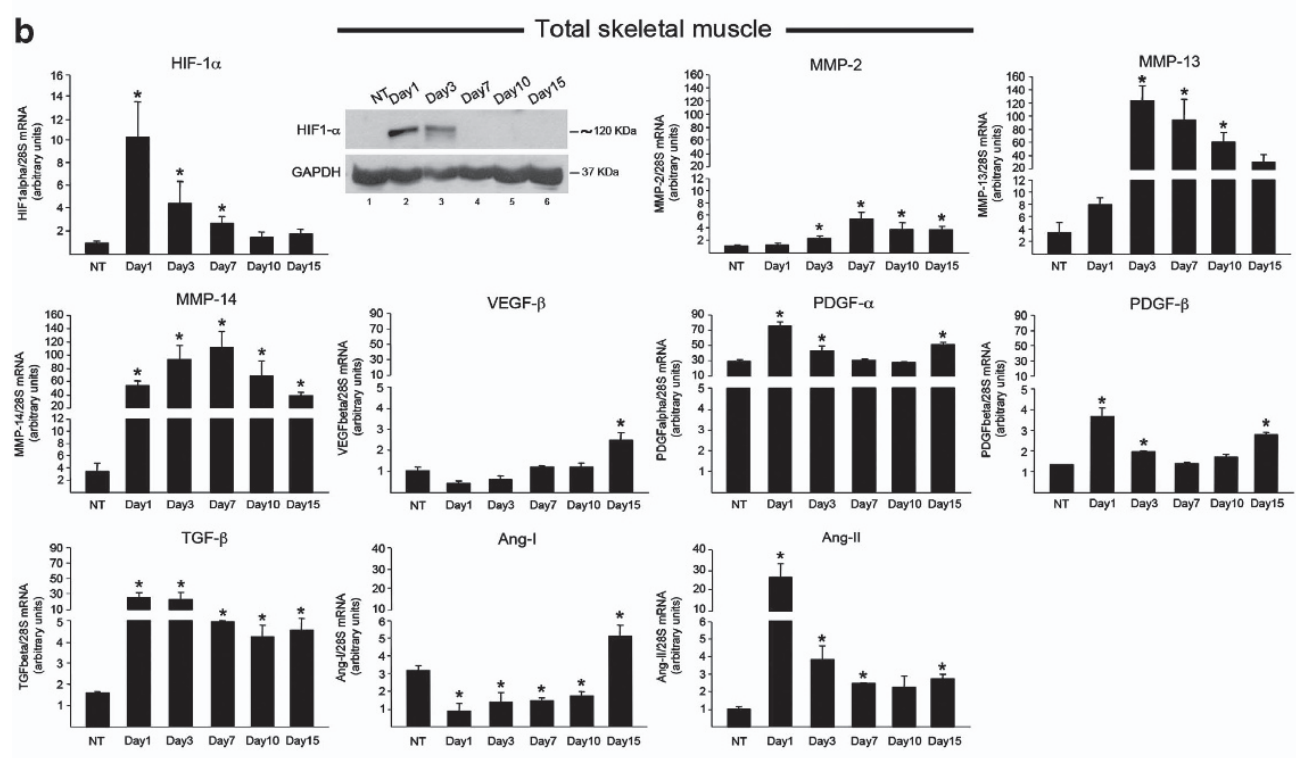

c Infiltrating leukocytes
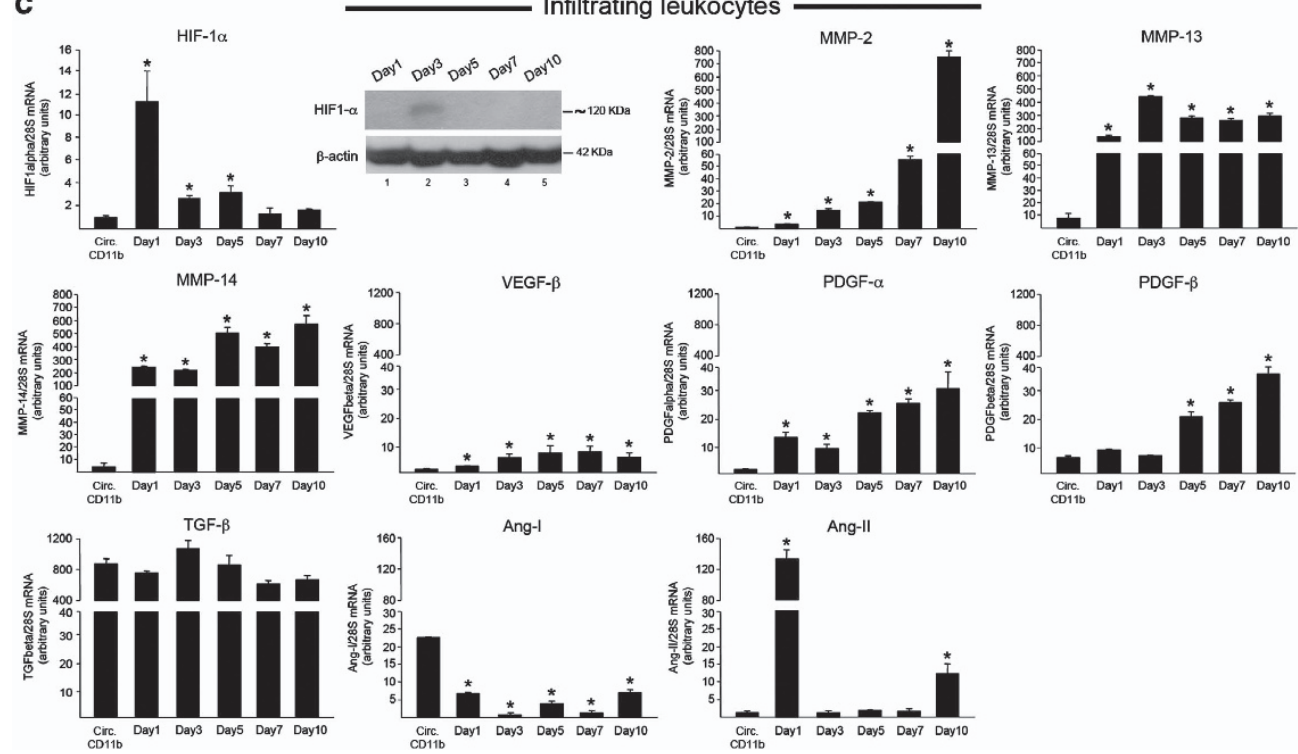
expression progressively decreased as the healing process is complete, while TNF- $\alpha$ showed a early and transient expression at day 1 (Supplementary Figure S2).

MPs are necessary for efficient vessel remodeling upon muscle damage. To verify the role of infiltrating MPs in vessel remodeling, we ablated phagocytic cells by treating mice with clodronate $(\mathrm{Cll})$ encapsulated into liposomes. ${ }^{14}$ Sham liposomes (sham) or Cll were intravenously injected 1 day before the CTX injury and every 3 days after, for the entire duration of the experiments. The treatment was effective: $\mathrm{F} 4 / 80$ circulating phagocytes and $\mathrm{CD} 68^{+}$infiltrating MPs were significantly less numerous in Cll-treated than in sham-treated animals throughout the regeneration process, as assessed by FACS on blood samples (F4/80 ${ }^{+}$cells reduction in Cll-treated mice with respect to sham-treated controls: $85 \pm 2.5 \%$ at day $5 ; 76.5 \pm 5 \%$ at day $7 ; 24 \pm 6 \%$ at day $10 ; \quad P<0.05$; Supplementary Figure $\mathrm{S} 4 \mathrm{~A}$ ) or by IF on muscle sections $(71 \pm 7 \%$ at day $5 ; 52 \pm 4 \%$ at day 7 , $68 \pm 2 \%$ at day 10 in Cll-treated mice with respect to shamtreated controls, $P<0.05$ ), respectively (Supplementary Figures S4B and C). All sub-populations of polarized MP, identified by the expression of CD86 (classically activated) or CD163 and CD206 (alternatively activated), ${ }^{22,23}$ were reduced upon $\mathrm{Cll}$ treatment (Supplementary Figures S4B and C).

The depletion of MPs resulted in a delay in fiber regeneration (Supplementary Figure S4D) and hampered the vascular remodeling of the tissue, as indicated by immunohistochemistry (IHC) analysis for CD31 (Figure 3a). In MP-depleted mice, the neovasculature was disorganized and jeopardized: between 5 and 10 days after damage, number and area of capillaries both in TA and triceps (Figure $3 a$ ) were significantly reduced. Notably, 10 days after damage TA muscles of MP-depleted mice comprised a relatively high number of capillaries (Figure 3b). However, vessels were mostly isolated and showed a striking reduction of the lumen diameter (Figure 3c). At day 15, vascular remodeling was complete in muscles of both sham-treated and MP-depleted animals (Figure 3 ).

MP infiltration regulates the fate of endothelial-derived
progenitor and inhibits mesenchymal accumulation
and fibrosis. In sham-treated mice, postnatal endothelial progenitors contribute to neo-angiogenesis during muscle healing: indeed $\mathrm{EYFP}^{+}$or $\beta$-Gal ${ }^{+}$cells almost completely overlap with $\mathrm{CD} 31^{+}$cells (Figure $2 \mathrm{a}$, Figures $4 \mathrm{a}$ and b). On the contrary, in the absence of MPs the number of CD31 ${ }^{+}$ $\mathrm{EYFP}^{+}$or $\mathrm{CD}^{+} 1^{+} \beta$-Gal ${ }^{+}$cells in the muscle was decreased (Figures $4 a$ and b): from day 7 after injury a high number of $\mathrm{CD}^{-} 1^{-} \mathrm{EYFP}^{+}$or $\mathrm{CD}^{-} 1^{-} \beta$-Gal ${ }^{+}$endothelialderived progenitors fail to contribute to neo-angiogenesis or to yield capillaries (Figures $4 a$ and $b$ ).

To get insights into the fate of these CD31- ${ }^{-}$EFFP $^{+}$ endothelial-derived progenitors in MP-depleted muscle, we measured the expression of different cell-specific markers. EndoMT has been described to occur in several tissues, still never in skeletal muscle. ${ }^{17,24,25} \mathrm{MP}$ depletion led to an accumulation of total mesenchymal, pericytes or interstitial cells (1.6-fold increase in Cll-treated mice versus sham controls), as assessed by quantification of $\alpha-\mathrm{SMA}^{+}$and $\mathrm{NG}_{2}{ }^{+}$cells by IF (Figure $5 \mathrm{~b}$, left panels) and of $\mathrm{NG}^{+} /$or $\mathrm{SMC} .6^{+} / \mathrm{CD} 31^{-} \mathrm{CD} 45^{-}$cells by FACS (Figure $5 \mathrm{c}$, left panels). Interestingly, while the number of $\alpha-\mathrm{SMA}^{+}$showed a continuous increase until day 21 , the total number of $\mathrm{NG}^{+}$ cells (the pericyte fraction) dropped after day 18 (Figures $5 b$ and $\mathrm{c}$, left panels); this may be an indication of vessel instability, still to investigate.

In agreement with the accumulation of mesenchymal cells, $\mathrm{EYFP}^{+}$or $\beta$-Gal ${ }^{+}$postnatal endothelial progenitors yield more effectively NG2, CD31- ${ }^{-} D 45^{-}$SMC2 $^{-} 6^{+}$or $\alpha$-SMA, mesenchymal/interstitial/pericyte cells in Cll-treated mice with respect to controls, as assessed by either IF or FACS analysis (Figures $5 \mathrm{a}-\mathrm{c}$, right panels): 10 days after damage $26 \% \pm 7$ of the $\beta$-Gal ${ }^{+}$cells in the muscle were NG2 ${ }^{+}$and the $27.4 \%$ \pm 4.5 were $\alpha$-SMA ${ }^{+}$. (Figure $5 \mathrm{~b}$ ) upon MP depletion and the percentage of $\beta$-Gal ${ }^{+} \alpha$-SMA ${ }^{+}$cells further increased 21 days after damage $\left(34.7 \% \pm 2\right.$ on total $\beta$-Gal ${ }^{+}$and $30 \% \pm 2.5$ on total $\alpha-\mathrm{SMA}^{+}$cells). A similar result was observed when measuring the percentage of $\beta-\mathrm{Gal}^{+} \mathrm{NG}^{+}$cells, taking into consideration the decline in total $\mathrm{NG}^{+}{ }^{+}$cells (Figure $5 \mathrm{~b}$, right panels).

qPCR analysis confirmed that, upon MP depletion, EYFP ${ }^{+}$ endothelial progenitor-derived cells, FACS sorted 10 days after damage, expressed decreased levels of endothelialspecific markers (VE-Cadherin and CD31) and increased levels of collagen I, a gene specific of mesenchymal/ fibroblastic cells, involved in the onset of fibrosis (Figure 5d).

Figure 2 Pro-angiogenic genes are upregulated during skeletal muscle regeneration. (a) IF on TA cross-sections from 2-month-old Cdh5-CreER ${ }^{\mathrm{T} 2}$; R26R-NGZ mice before and 5, 7 and 15 days after CTX damage. Representative images of sections immunostained for CD31 (red) overlayed to the nuclear X-Gal staining (converted in pseudo fluorescent green signal), showing colocalization of labeled cells with CD31. Magnification $\times 20$. Scale bar: $50 \mu$ m. (b) TA muscles from 2-month-old Cdh5-CreER ${ }^{\mathrm{T} 2}$; R26R-EYFP mice were collected immediately before and 1, 3, 7, 10 and 15 days after injection of CTX. Total muscle lysates were collected and processed for RNA and protein extraction. Real-time PCR analyses for HIF1- $\alpha$, MMP-2, MMP-13, MMP-14, VEGF- $\beta$, PDGF- $\alpha$, PDGF- $\beta$, TGF- $\beta$, Ang-I and Ang-II mRNA expression were performed. Results were normalized to $28 \mathrm{~S}$ mRNA levels and expressed as relative fold changes compared with undamaged muscles (NT). The data are expressed as means \pm S.E.M. ( $n=6$ ). Statistically significant differences are indicated $\left({ }^{*} P<0.05\right.$ versus NT). Western blot analysis of HIF1- $\alpha$ expression on total healthy muscle (NT, lane 1$)$ and at different time point after CTX injection (days 1 to 15, lanes 2 to 6) was performed. Results are representative of three independent experiments. (c) Quadriceps and TA muscles from 2-month-old Cdh5-CreER ${ }^{\text {T2 }}$; R26R-EYFP mice were collected 1, 3, 5, 7 and 10 days after injection of CTX. Muscles were digested to isolate CD11b ${ }^{+}$cells by magnetic bead sorting and processed for RNA and protein extraction. Real-time PCR analyses for HIF1- $\alpha$, MMP-2, MMP-13, MMP-14, VEGF- $\beta$, PDGF- $\alpha$, PDGF- $\beta$, TGF- $\beta$, Ang-I and Ang-II mRNA expression were performed. Results were normalized to $28 \mathrm{~S}$ mRNA levels and expressed as relative fold changes compared with $\mathrm{CD} 11 \mathrm{~b}{ }^{+}$cells retrieved from peripheral blood (circ. CD11 ${ }^{+}$). The data are expressed as means \pm S.E.M. $(n=6)$. Statistically significant differences are indicated $\left({ }^{*} P<0.05\right.$ versus circ. CD11 ${ }^{+}$). Time course changes in the expression of HIF1- $\alpha$ were evaluated by western blot analysis on muscle-infiltrating CD11b ${ }^{+}$cells at different time points of CTX injection. Results are representative of two independent preparations 

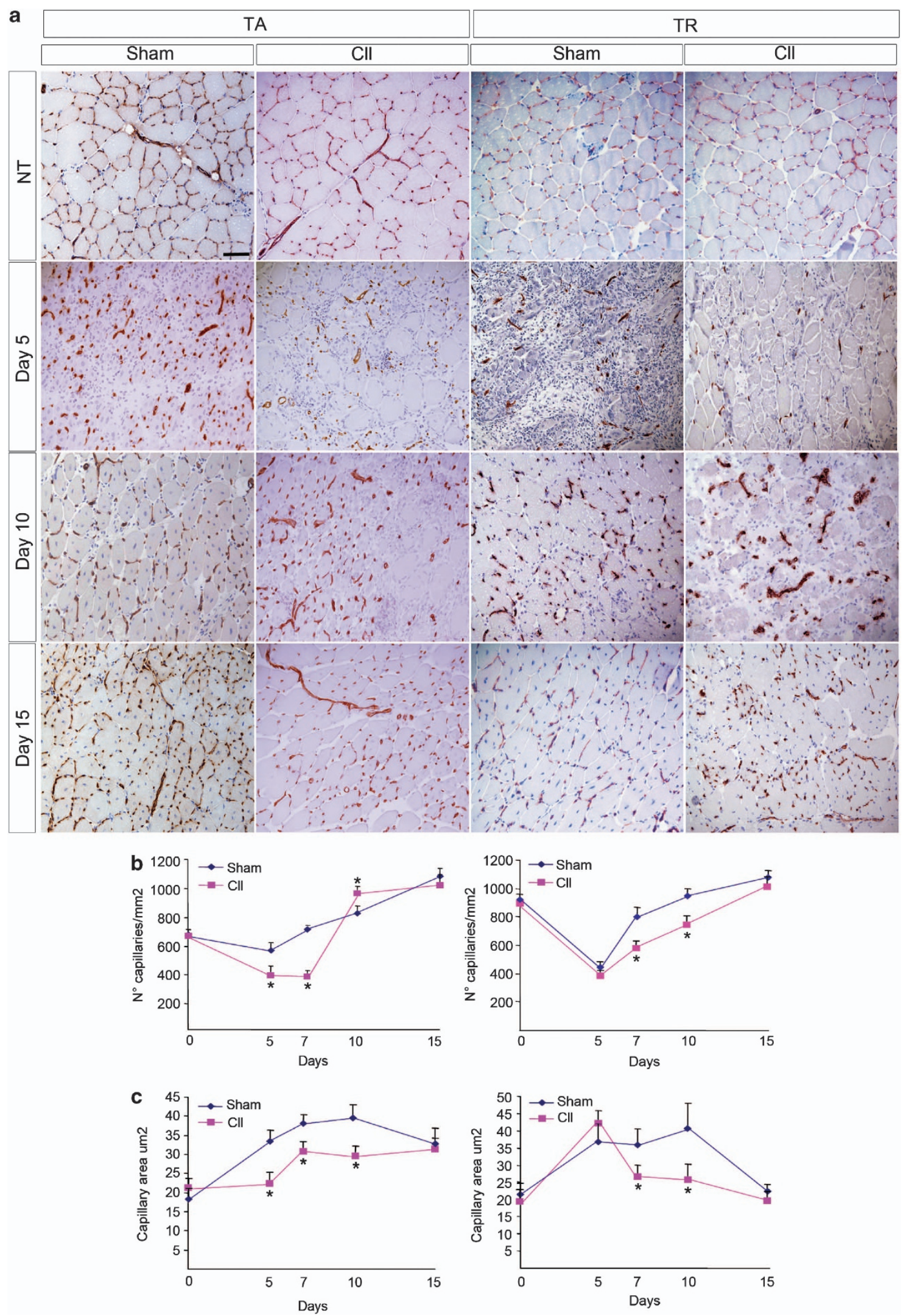
These results suggest that in the absence of MPs EndoMT is occurring.

Among the mesenchymal progenitor cells that reside in the muscle, PDGFR $-\alpha^{+}$fibroadipogenic progenitors (FAPs) have been described to expand upon muscle damage and to contribute to fibrosis and fat accumulation in ageing and disease. ${ }^{26-28}$ In Cll-treated mice, we observed the expected accumulation of interstitial PDGFR- $\alpha^{+}$cells at 3-7-10 days after CTX damage: their number was always similar to sham-treated mice (Supplementary Figure S5), indicating FAPs expansion is not affected by phagocyte depletion. In addition, we did not observed colocalization of EYFP or $\beta$-Gal with PDGFR $\alpha$, thus endothelial-derived progenitors do not differentiate into FAP (Supplementary Figure S5).
In conditions in which inflammatory phagocytes did not deliver appropriate signals to progenitor cells within the regenerating muscle, we therefore observed that endothelialderived progenitors underwent EndoMT and contributed to the uncontrolled expansion of fibroblast/mesenchymal cells, ultimately leading to collagen accumulation. Indeed, 21 days after damage, muscles were characterized by non-homogenous regenerating fibers surrounded by large areas of fibrosis and fat, while muscles of sham-treated mice were devoided of fibrosis and showed complete regeneration (Figures $6 a$ and b).

MP depletion affects angiogenic and fibrogenic signaling. To get insights into the mechanism through which infiltrating MPs restrict EndoMT, we analyzed the
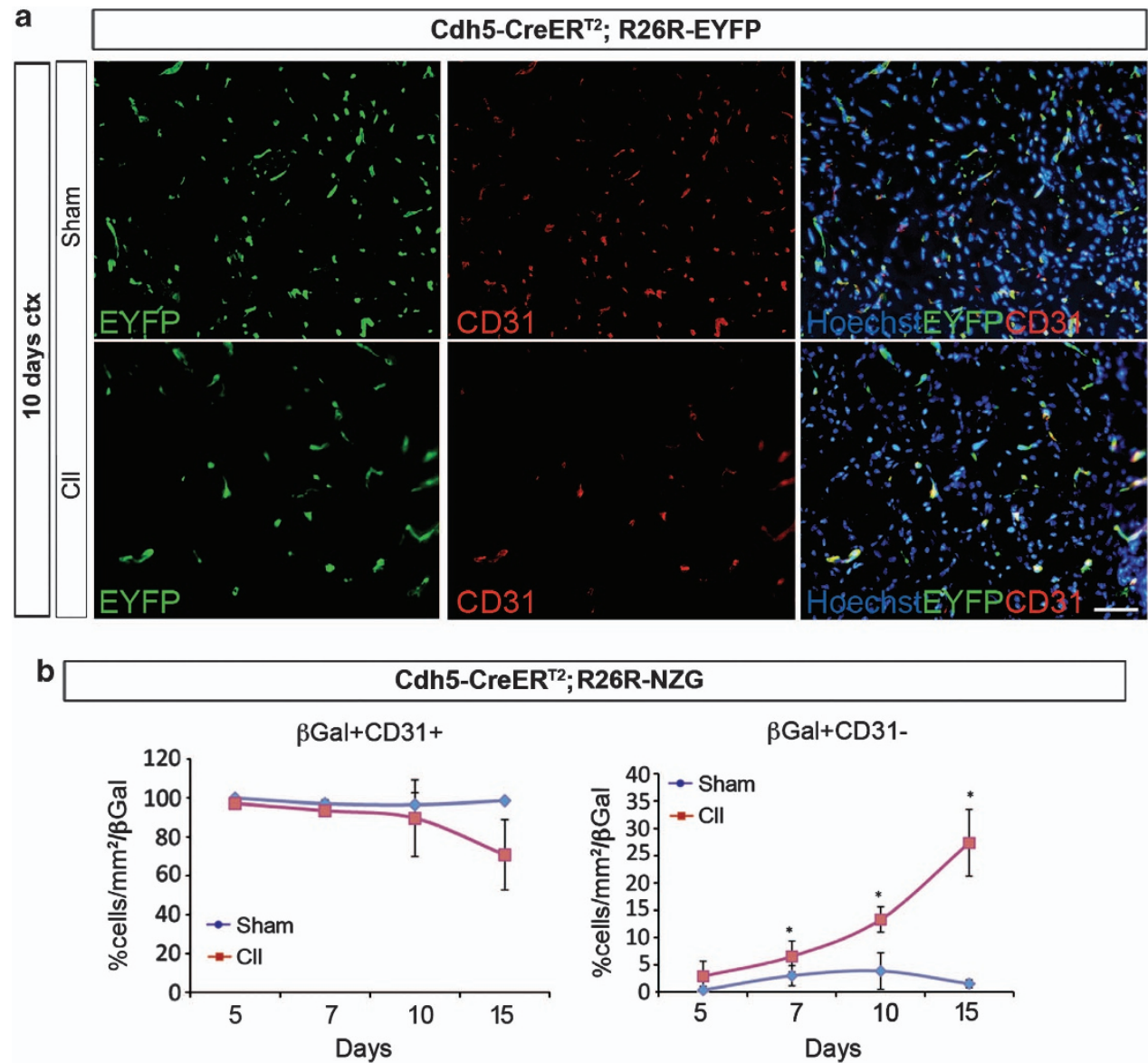

$\beta G a l+C D 31-$

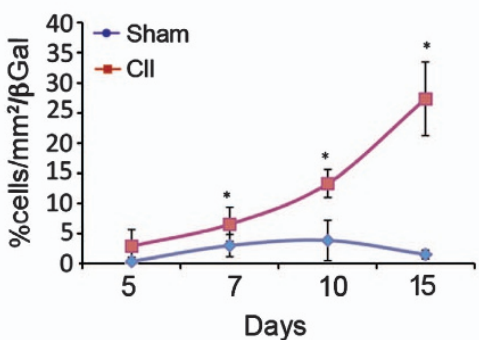

Figure 4 VE-Cad + derived cells show decrease contribution to endothelium and neo-angiogenesis in Cll-treated mice. (a) Representative images of cross-sections TA muscle immunostained for EYFP (green) and CD31 (red) from sham- and Cll-treated Cdh5-CreER ${ }^{\text {T2 }}$;R26R-EYFP mice 10 days after CTX. Magnification $\times 20$. Scale bar: $50 \mu \mathrm{m}$. (b) Quantification of $\beta$-Gal ${ }^{+} \mathrm{CD} 31^{+}$and $\beta$-Gal ${ }^{+} \mathrm{CD} 31^{-}$cells measured as the percentage of positive cells on the total $\beta$-Gal ${ }^{+}$cells per square millimeter in immunostained TA muscle sections from sham- and Cll-treated Cdh5-CreER ${ }^{\text {T2}}$; R26R- NZG mice, 5, 7, 10, 15 days after CTX injection. Data are expressed as means \pm S.E.M. $(n=3)$. Statistically significant differences are indicated (sham versus $\left.\mathrm{Cll}{ }^{*} P<0.05\right)$

Figure 3 MP depletion impairs neo-angiogenesis in regenerating skeletal muscles. (a) Skeletal muscles of sham liposome- and Cll-treated mice were acutely injured by injection of CTX, and retrieved immediately before and 5, 10 and 15 days after damage. Panels show representative images of TA (left panels) and triceps (TR) (right panels) muscle cross-sections immunostained for CD31. Magnification $\times 20$. Scale bar: $50 \mu \mathrm{m}$. (b and $\mathbf{c}$ ) Density and area of blood vessels were measured in healthy and CTX-treated TA and TR muscles of sham- and Cll-treated mice. The capillary vessel density (b) and the mean capillary area (c) were evaluated by digital image analysis of randomly selected muscle sections immunostained for CD31. The capillary vessel density was expressed as number of capillaries per square millimeter. The data are expressed as means \pm S.E.M. $(n=3)$. Statistically significant differences are indicated (sham versus $\left.\mathrm{Cll}{ }^{*} P<0.05\right)$ 


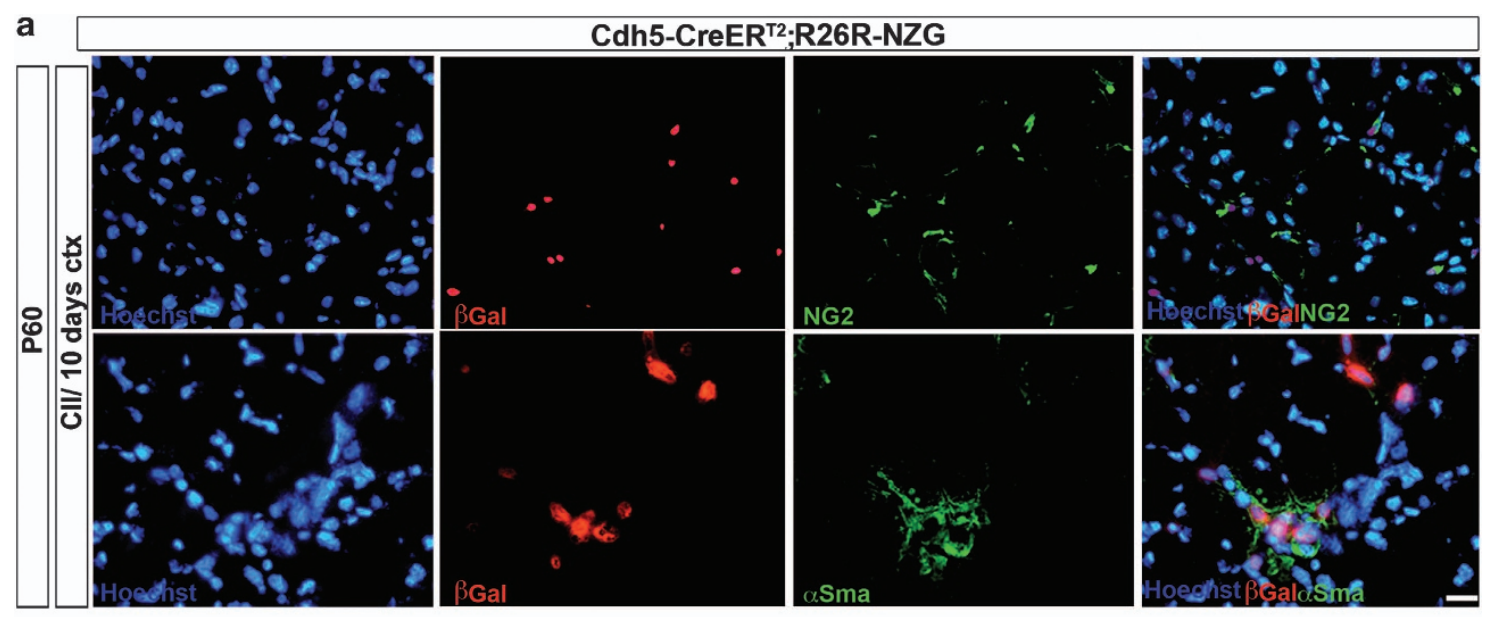

b $\quad$ Cdh5-CreER $^{\text {T2}} ;$ R26R-NZG
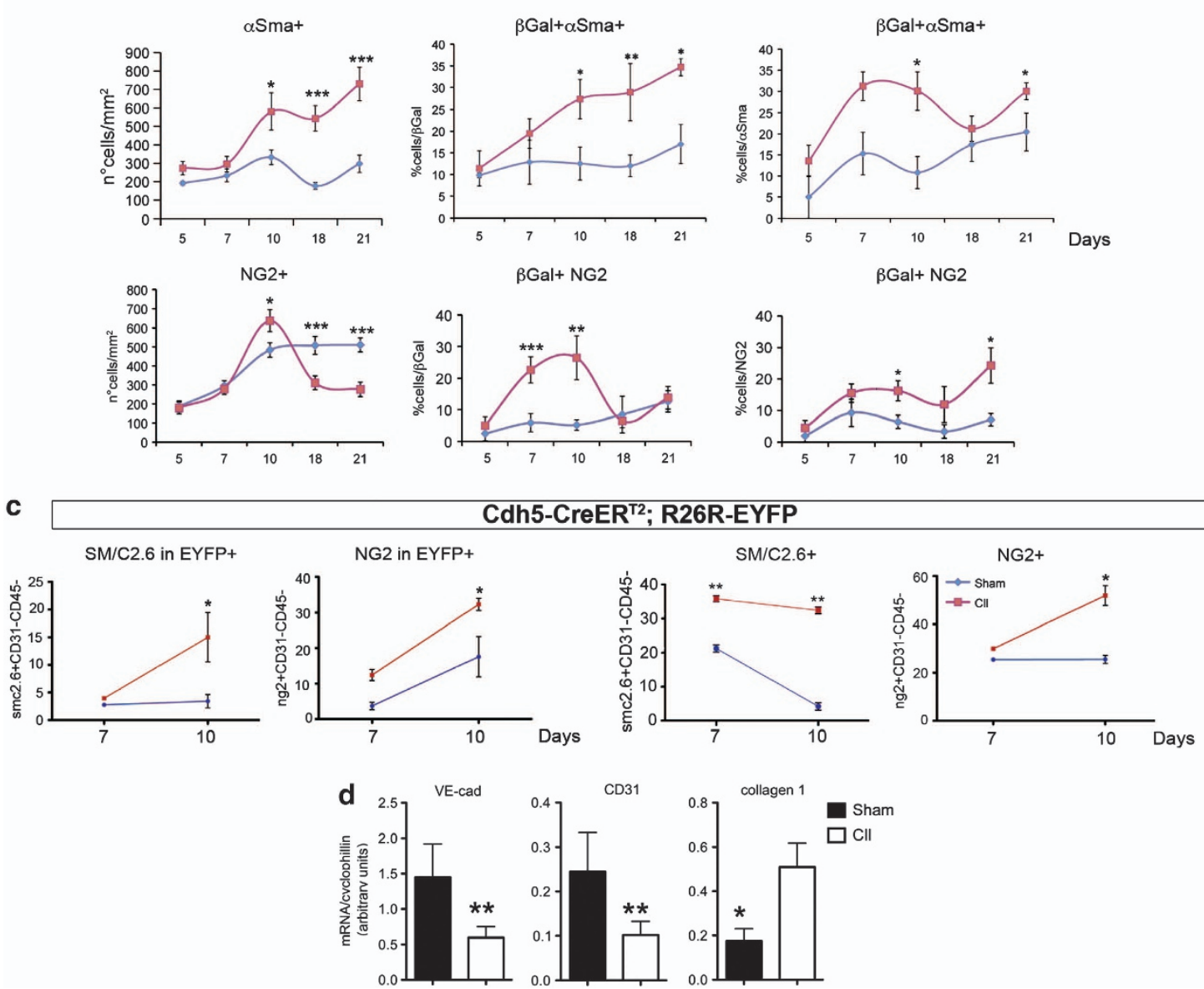

Figure 5 VE-Cad + derived cells express mesenchymal markers after $\mathrm{Cll}$ treatment. (a) Representative images of triceps muscle cross-sections from sham- and Cll-treated Cdh5-CreER ${ }^{T 2}$;R26R-NZG immunostained and NG2 or $\alpha$-SMA (green) overlayed to the nuclear X-Gal staining (converted in pseudo fluorescent red signal), 10 days after CTX injury. Magnification $\times 40$. Scale bar: $20 \mu \mathrm{m}$. (b) Quantification of the total NG2 ${ }^{+}$or $\alpha$-SMA ${ }^{+}$cells in the muscle of sham-and Cll-treated Cdh5-CreER ${ }^{\text {T2. }}$ R26R-NZG mice is shown in left panels as the number of positive cells per square millimeter. Central panels show quantification of $\beta$-Gal ${ }^{+} \mathrm{NG}^{+}{ }^{+}$or $\beta$-Gal ${ }^{+} \alpha$-SMA ${ }^{+}$cells measured as the percentage of positive cells on the total $\beta$-Gal ${ }^{+}$cells. Right panels show the percentage of double positive cells among NG2 ${ }^{+}$or $\alpha$-SMA ${ }^{+}$cells $(n=3$, sham versus $\mathrm{Cll}{ }^{*} P<0.05$; ${ }^{* *} P<0.01$; ${ }^{* \star} P<0.005$ ). (c) Quadriceps muscles from sham- and Cll-treated Cdh5-CreER ${ }^{T 2} ;$ R26R-EYFP were collected 7 and 10 days after CTX, digested, and single-cell suspensions were analyzed by flow cytometry for the expression of EYFP, SMC2.6 and NG2. CD45- CD31- cells are identified, and the percentage of cells with a compatible side scatter (SSC-A) and expressing SMC2.6 or NG2 alone or co-expressing EYFP were calculated. The data are expressed as means \pm S.E.M. $(n=3)$. Statistically significant differences are indicated (sham versus $\left.\mathrm{Cll}{ }^{*} P<0.05 ;{ }^{*} P<0.01\right)$. (d) Real-time $\mathrm{PCR}$ analysis performed on $\mathrm{cDNA}$ obtained from RNA of EYFP ${ }^{+}$cells sorted from TA, triceps and quadriceps muscles from sham- and Cll-treated Cdh5-CreER ${ }^{\top 2}$; R26R-EYFP mice 10 days after CTX injection. The data are normalized on cyclophillin A expression. Statistically significant differences are indicated. The data are expressed as means \pm S.E.M. $(n=4)$; (sham versus $C \|{ }^{*} P<0.05$; $\left.{ }^{* *} P<0.01\right)$ 


\section{a}

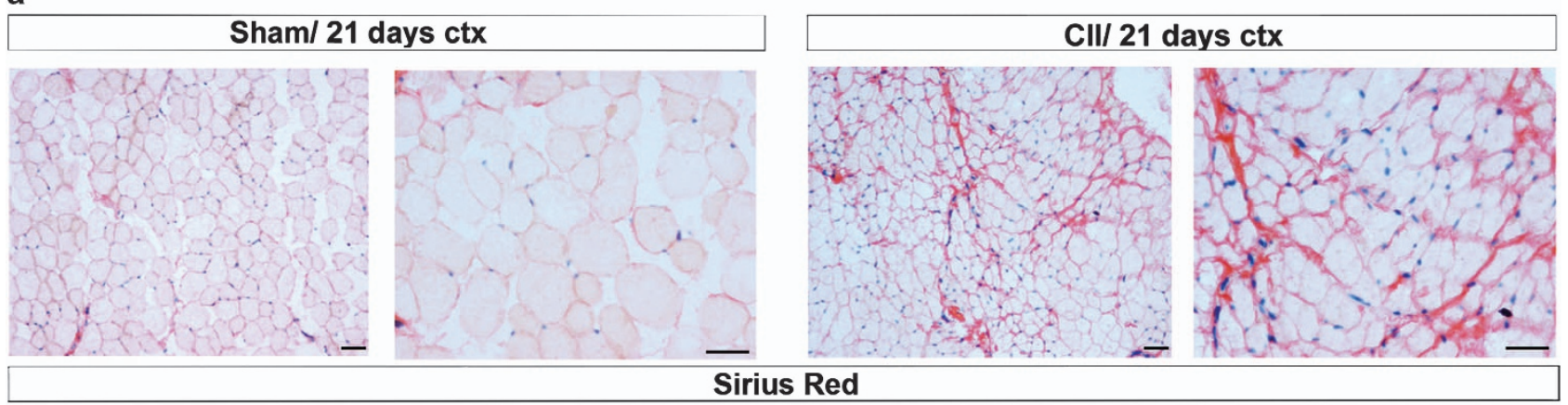

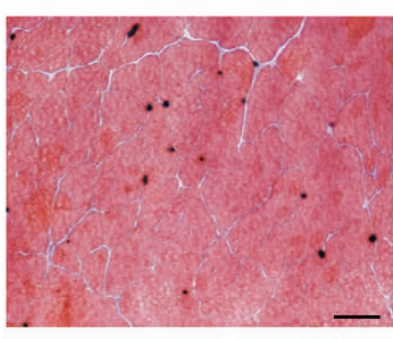

Masson

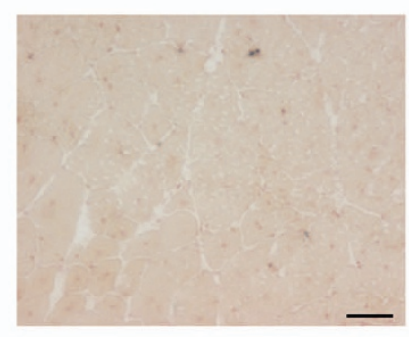

Red 0

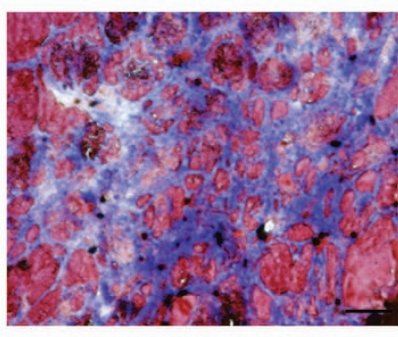

Masson

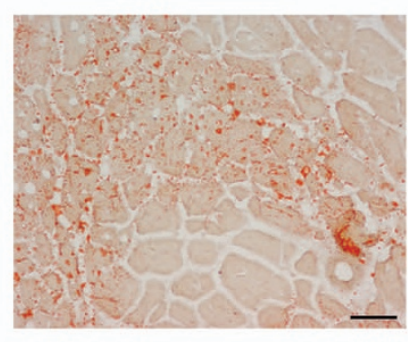

Red O b

\section{Fibrosis}

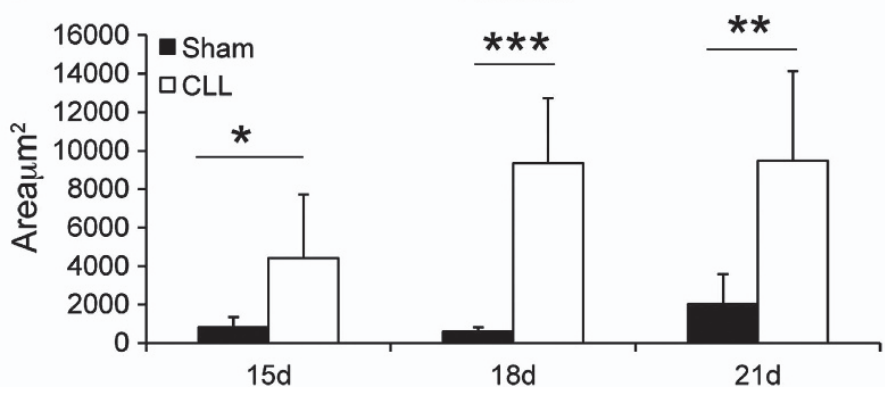

Figure 6 MP depletion leads to incoming fibrosis. (a) Sirius red, Masson's trichromic and Red O staining of representative TA sections from Cll-untreated/treated Cdh5CreER $^{\text {T2; }}$ R26R-NZG mice 21 days after CTX injection, showing the accumulation of excess fibrous connective tissue and of adipocytes in Cll-treated muscle. Magnification $\times 10$ and $\times 20$. Scale bar: $50 \mu \mathrm{m}$. (b) Fibrosis at 15, 18 and 21 days after ctx, in sham- and Cll-treated triceps, was quantified by digital image analysis of randomly selected muscle sections stained for Sirius red. Fibrosis was expressed as area per $\mu \mathrm{m}^{2}$. The data are expressed as means \pm S.E.M. $(n=3)$. Statistically significant differences are indicated (sham versus $\mathrm{C} \|{ }^{*} P<0.05$; ${ }^{* \star} P<0.01 ;{ }^{* * \star} P<0.005$ )

expression of growth factors, cytokines, proteases and chemokines in the healing muscle from day 5 , a time after which we start observing mesenchymal transition of endothelial progenitors (Figures 7a-c). Upon MPs depletion, HIF1- $\alpha$ mRNA levels were increased and Ang-II expression was still upregulated at day 7 , probably due to the persistence of hypoxia. In contrast, the expression of VEGF, PDGF- $\alpha$ PDGF- $\beta$, IL-10 and TNF- $\alpha$ was downregulated at all times (Figure $7 \mathrm{a}$ and Supplementary Figure S2).

Expression of MMP2, MMP13 and MMP14 between 5 and 15 days after injury was reduced in Cll-treated mice in agreement with an inefficient fibrolitic activity (Figure $7 \mathrm{~b}$ ).

TGF- $\beta$ /bone morphogenetic protein (BMP)/SMAD signaling is the main pathway implicated in EndoMT. ${ }^{29,30}$ We detected no significant differences in the expression of BMP-2 and BMP-4 in MP-depleted mice with respect to controls, while BMP-6 appeared to be overexpressed in Cll-treated mice 15 days after damage (Supplementary Figure S6). TGF- $\beta$ mRNA expression was lower at 5 and 10 days after injury, while at 7 days there was no difference between Cll-treated and control mice (Figure 7c). Conversely, the levels of TGF- $\beta$-activated protein was markedly upregulated 5 and 7 days after injury (Figure 6c), correlating with the onset of EndoMT. Interestingly Snail, a downstream target of TGF- $\beta$ signaling, was upregulated in MP-depleted muscles 5 and 10 days after damage (Figure 7a).

IF analysis using a phosphoSMAD2/3-specific antibody revealed an increased frequency of EYFP $^{+}$endothelialderived progenitors showing SMADs nuclear activity, in the muscle of Cll-treated mice (Figures $7 \mathrm{~b}$ and $\mathrm{c}$ ) indicating that the TGF- $\beta /$ SMAD signaling was specifically activated in endothelial-derived progenitor in the absence of MPs.

\section{Discussion}

The accumulation of fibrogenic cells is responsible for the production of ECM during the establishment of fibrosis in various degenerative diseases. The origin of these cells is still poorly understood. Here we demonstrate that in damaged skeletal muscle endothelial-derived progenitors can generate 
a
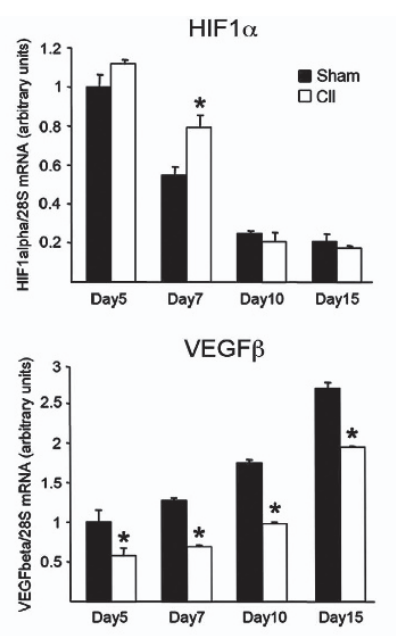

b

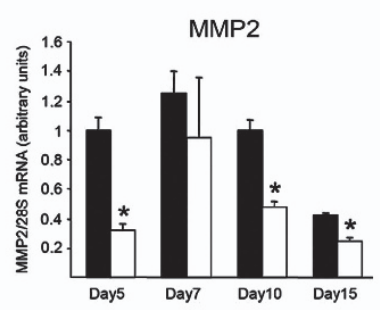

C

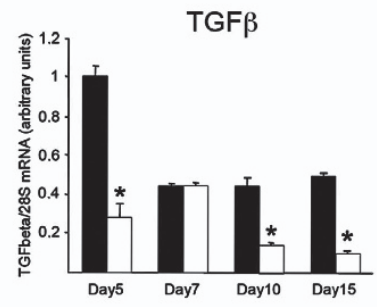

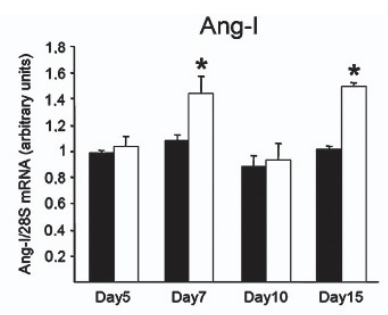

PDGF $\alpha$
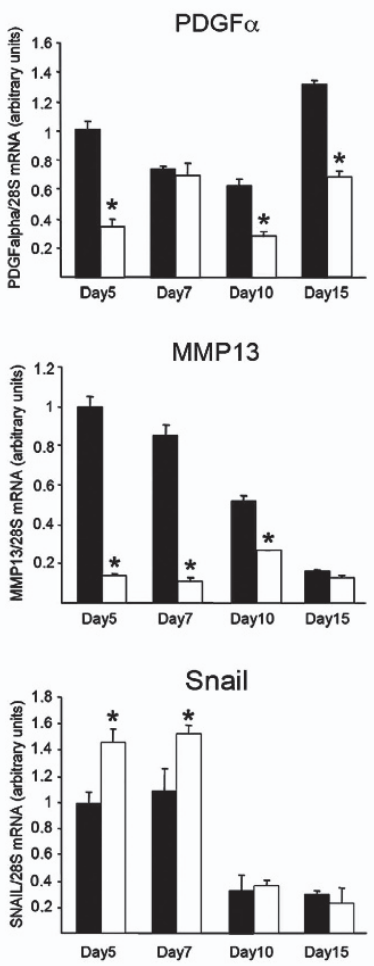

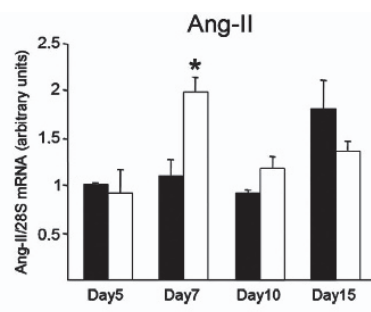

PDGF $\beta$
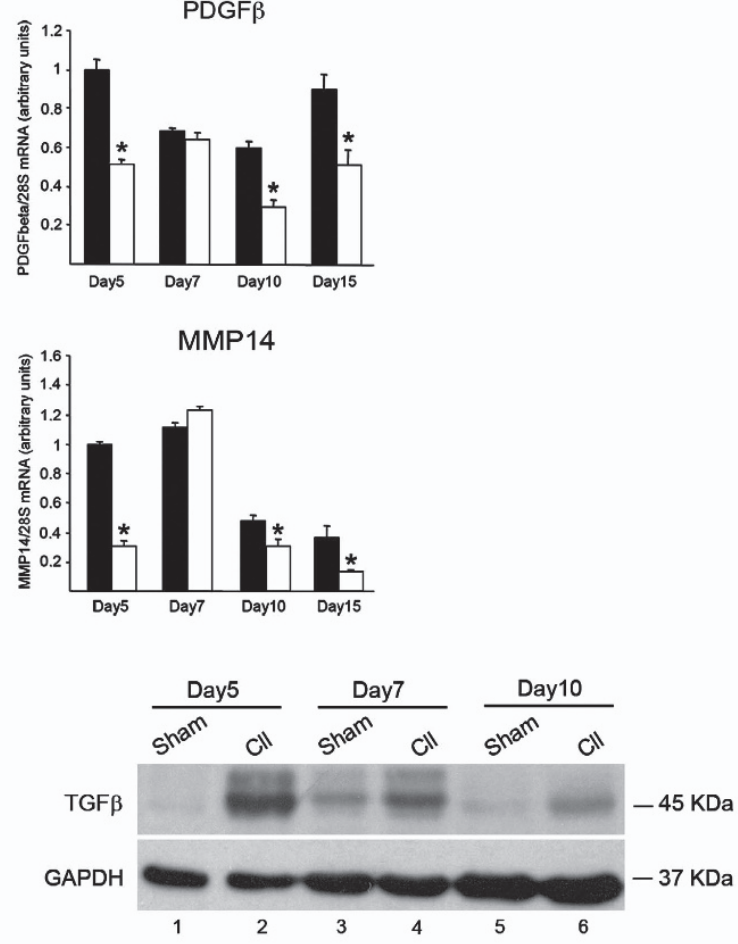

d

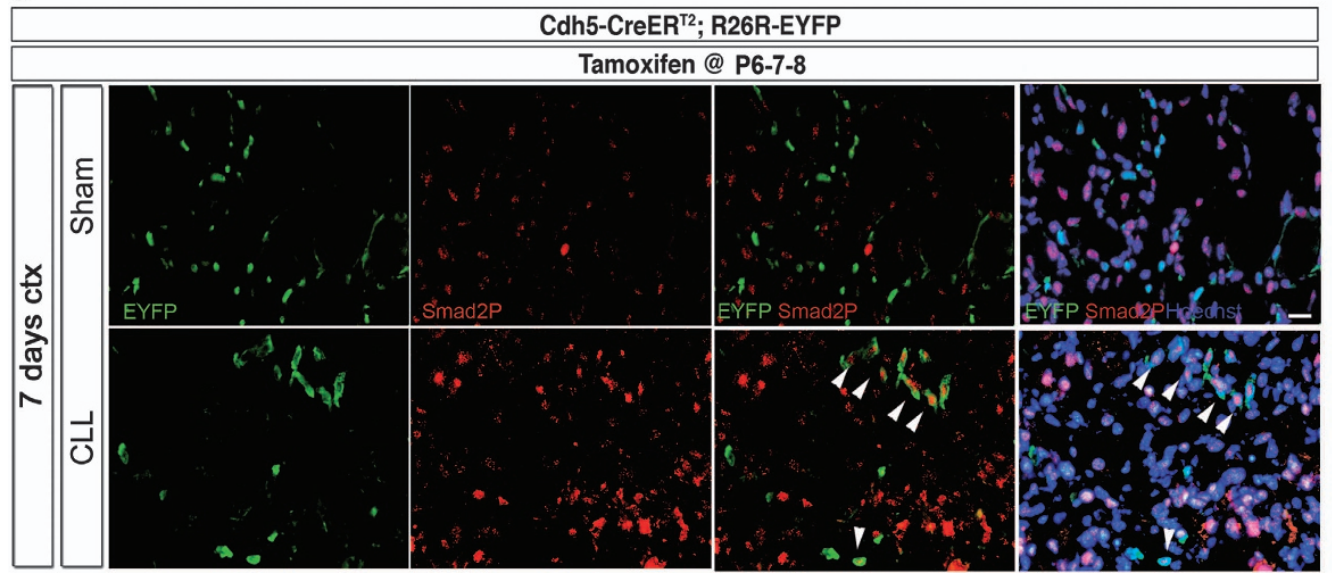

e $\quad$ EYFP $^{+}$Smad2P+

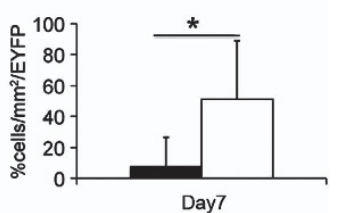

Figure 7 MP depletion affects pro-angiogenic factor production and TGF- $\beta / S M A D$ signaling during muscle healing. (a-c) TA muscles were collected from sham and Cll-injected mice 5, 7, 10 and 15 days after CTX injection. Muscles were totally lysated and processed for RNA extraction. Real-time PCR analyses for mRNA expression of HIF1- $\alpha$, Ang-I, Ang-II, PDGF- $\alpha$, PDGF- $\beta$, VEGF- $\beta$ (a), MMP-2, MMP-13, MMP-14 (b), TGF- $\beta$ and Snail (c) were performed. Results were normalized to $28 \mathrm{~S}$ mRNA levels and expressed as relative fold changes compared with sham-treated mice 5 days after damage. The data are expressed as means \pm S.E.M. $(n=5)$. Statistically significant differences are indicated (sham versus $\mathrm{Cl}{ }^{*} P<0.05$ ). Western blot analysis of TGF- $\beta$ expression was performed on total muscle lysates from sham (lanes 1,3 and 5 ) and $\mathrm{Cll}$ (lanes 2, 4 and 6) treated mice, 5 days (lanes 1 and 2), 7 days (lanes 3 and 4) and 10 days (lanes 5 and 6 ) after CTX injection. Results are representative of three independent experiments. Day $5 \mathrm{Cll}$ versus sham fold change 5.4 ; day $7 \mathrm{Cll}$ versus sham fold change 2.8. (d) Representative images of cross-sections triceps muscle immunostained for EYFP (green) and phospoho-SMAD (red) from sham- and Cll-treated Cdh5-CreER ${ }^{T 2}$;R26R-EYFP mice 7 days after CTX. Arrows point to EYFP ${ }^{+}$cells showing nuclear SMAD2/3P signal. Magnification $\times 40$. Scale bar: $50 \mu \mathrm{m}$. (e) Quantification of EYFP ${ }^{+}$phospho-SMAD2 ${ }^{+}$cells measured as the percentage of positive cells among the total EYFP $^{+}$cells per square millimeter in immunostained triceps muscle sections from sham- and Cll-treated Cdh5-CreER ${ }^{\text {T2}}$; R26R-EYFP mice, 7 days after CTX injection. Data are expressed as means \pm S.E.M. $(n=3)$. Statistically significant differences are indicated (sham versus $\left.\mathrm{Cll}{ }^{*} P<0.05\right)$ 
mesenchymal/fibrogenic cells, when inflammatory infiltration is impaired.

Muscle damage triggers a series of coordinated events aimed at remodeling and healing of the tissues. These comprise the recruitment of inflammatory cells that first clear the debris, then contribute to the activation and differentiation of the muscle stem cells and their fusion in new myofibers. ${ }^{31}$ Neo-angiogenesis is also necessary to establish a new vascular network. Another crucial component required to sustain and act as scaffold for the new myofiber formation is the ECM that is first derived from the necrotic fibers and subsequently secreted from the myofibroblasts that proliferate in situ or migrate in the healing muscle. ${ }^{32}$

Perturbation of any of these steps can result in an ineffective muscle healing, typically characterized by persistent myofiber degeneration, inflammation and fibrosis, resulting from a excessive accumulation of ECM components. ${ }^{33}$

By using an endothelial-specific lineage-tracing mouse model, we followed the fate of endothelial progenitors during muscle regeneration after an acute injury. In physiological condition, when polarized MPs infiltrate the tissue, the vast majority of these endothelial-derived cells contribute to the formation of a new capillary network. When we perturbed this process, by depleting circulating monocytes and infiltrating MPs, we observed delayed angiogenesis and myogenesis. In addition, the accumulation of infiltrating fibroblasts and collagen did not abate as regeneration occurred, leading to a persistent fibrosis.

Expression profile of candidate factors in MP-depleted muscle indicated that one of the possible cause of unremitting collagen accumulation is the decreased level of some MMPs. ${ }^{21}$ In particular, MMP13 has been described to be expressed not only by MPs but also by migrating fibroblasts and muscle satellite cells during skeletal muscle regeneration, and its persistent expression during all phases of regeneration suggests a dual role in supporting cell movements and tissue healing as well as in long-term collagen remodeling and scar reduction. ${ }^{34} \mathrm{~A}$ similar effect of MMP14 (MT1-MMP1) and MMP2 can be envisaged. ${ }^{33}$ Mice deficient in the cell-associated MMP-MT1 exhibited smaller and centrally nucleated myofibers compared with normal mice, and treatment with active MT1-MMP can effectively reduce muscle scarring. ${ }^{35,36}$ The decreased expression of MMP13, MMP14 and MMP2 in Cll-treated mice, due to decrease production from MPs and muscle cells, could correlate with the delay in regeneration and collagen deposition.

Collagen accumulation is also due to the increased amount of resident fibroblasts/mesenchymal progenitor cells. In addition, quiescent FAPs represent a significant fraction of fibrogenic cells in adult skeletal muscle. ${ }^{26,27}$ FAP population did indeed expand upon muscle damage, to decline afterward, but their number was not affected by MP depletion, in agreement with the fact that they are regulated by eosinophils and not by MPs. ${ }^{37}$ Moreover, we demonstrated that FAPs do not show lineage continuity with endothelial-derived progenitors.

In Cll-treated mice, endothelial-derived progenitors appeared to contribute markedly less to capillary formation and neo-angiogenesis, possibly exacerbating the delay in these processes. More crucially, they downregulated the expression of endothelial markers, whereas upregulating mesenchymal markers, including collagen I. In particular, from day 7 after damage in Cll-treated mice, we observed approximately the doubling of $\beta$-Gal cells expressing NG2/ $\alpha$ SMA while being negative for CD31, with respect to controls, suggesting that EndoMT is occurring. Although in the past, EndoMT was believed to be a rare phenomenon confined to embryonic development, its existence in the adult vasculature has been reported. Recent studies have demonstrated that EndoMT may be an important mechanism in the pathogenesis of pulmonary, cardiac, kidney fibrosis, and in the onset and progression of cerebral cavernous malformations, and may represent a novel therapeutic target for fibrotic disorders. ${ }^{24,25,29,38,39}$

To our knowledge, this is the first description of EndoMT occurring in the adult skeletal muscle and may concur to the severity of many degenerative diseases, including muscular dystrophy.

In contrast to epithelial to mesenchymal transition (EMT), very few studies have addressed the molecular mechanisms underlying EndoMT. TGF- $\beta$ signaling has a crucial role in the transformation of mouse embryonic stem cell-derived endothelial cells or human dermal microvascular endothelia into cells that express mesenchymal markers ( $\alpha$-SMA, SM22 $\alpha$ and calponin) and loose/co-express endothelial markers. ${ }^{30,40}$ In our conditions, BMPs mRNA levels were not affected by MP depletion except at later stages: BMP-6 increase in Cll-treated mice 15 days after damage could be a late secondary effect, since at this time fibrosis is already in progress and EndoMT has already occurred. Transcript levels of PDGF- $\alpha$ and $\beta$, factors also associated with fibroblasts activation and differentiation, ${ }^{32}$ were reduced as well as those of TGF- $\beta$. Interestingly, MP-depleted muscle contains higher levels of TGF- $\beta$-activated protein. Circulating inflammatory cells or mesenchymal cells have been proposed to be the source of TGF- $\beta .{ }^{17}$ In our model of MP depletion, the upregulation or increased release of TGF- $\beta$ protein has to be mediated by other cell types, as a secondary effect of the impaired signaling from inflammatory phagocytes.

Snail, a downstream target of TGF- $\beta /$ BMP pathway and required for $\mathrm{EndoMT}^{30}$ was consistently upregulated in muscles of Cll-treated mice. In these mice, nuclear pospho SMAD2/3 was found specifically in endothelial-derived progenitors, suggesting that EndoMT is triggered by the TGF- $\beta$ /BMP cascade.

Ang-II can also be implicated into this pathway and in fibrosis both in a TGF- $\beta$-dependent and -independent manner: it can influence not only TGF- $\beta$ production, but also lead to the nuclear translocation of phosphorylated SMADs. ${ }^{32,41}$ Ang-II expression was indeed increased in muscle of Cll-treated mice 7 days after damage, at the onset of the expansion of the endothelial-derived mesenchymal cells. In these mice, capillary network formation is delayed, and persistent hypoxia may contribute to the upregulation of Ang-II and consequently of HIF-1 $\alpha$. It is plausible that the SMAD-dependent EndoMT may be therefore also caused by direct or indirect activation of the pathway by hypoxiainduced signals.

Direct interference with Ang-II or treatment with TGF- $\beta$ neutralizing antibodies may clarify their specific role in EndoMT progression. 
The decreased expression of endothelial differentiation factor VEGF, and the anti-fibrotic cytokine IL-10 42,43 in MP-depleted mice could also contribute to the inhibition of endothelial differentiation and further enhance the mesenchymal transition of endothelial-derived progenitors.

In conclusion, our results suggest that infiltrating MPs represent a relevant endogenous source of cytokines and angiogenic factors, which support neo-angiogenesis during muscle regeneration by both sustaining the differentiation of endothelial-derived progenitors toward an endothelial fate and by preventing the formation of a fibrotic scar. It is tempting to speculate that in pathogenic conditions, when failure of correct MP infiltration occurs, the fate of endothelial-derived progenitors can be skewed to a fibroblastic phenotype, further contributing to an abnormal tissue remodeling.

Although more studies will be necessary to elucidate in detail the molecular mechanisms that underlie EndoMT in the skeletal muscle, our findings open the possibility that endothelial cells in the muscle as well as MPs may represent new targets for therapeutic intervention for several devastating diseases such dystrophy and other genetic myopathies as well as in aging.

\begin{abstract}
Materials and Methods
Mice. Transgenic mice have been previously described: Cdh5-CreER ${ }^{T 2,18}$ R26REYFP; ${ }^{19}$ R26-NZG. ${ }^{20}$ All procedures were performed in the animal facility of San Raffaele Scientific Institute in accordance with European Union guidelines and with the approval of the Institutional Ethical Committee (IACUC no. 489).
\end{abstract}

TAM injection. Cre recombination was induced in Cdh5-CreER ${ }^{\mathrm{T} 2}: \mathrm{R} 26 \mathrm{R}$ -

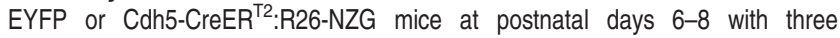
consecutive subcutaneus injections of TAM $(25 \mu \mathrm{l}$ Tam each, $10 \mathrm{mg} / \mathrm{ml})$.

Muscle injury. Mice (4-6 mice per group) were anesthetized and subsequently injected with CTX in different muscles (Naja mossambica mossambica, Sigma-Aldrich (St. Louis, MO, USA); $50 \mathrm{ml}, 15 \mu \mathrm{M}$ for TA and triceps muscles, $50 \mu \mathrm{M}$ for quadriceps muscles) and killed at 1, 3, 5, 7, 10, 15, 18 and 21 days after injury. For RNA analyses, muscles were snap frozen in liquid nitrogen. For histology, muscles were collected and embedded in OCT or directly frozen in liquid nitrogen cool isopentane.

Retrieval and purification of muscle-infiltrating MPs. Infiltrating cells were retrieved from damaged muscles 1, 3, 5, 7 and 10 days after sterile injury. Muscles were dissociated by enzymatic digestion with collagenase type $\mathrm{V}$ $(0.5 \mathrm{mg} / \mathrm{ml}$; Sigma-Aldrich) and dispase $(3.5 \mathrm{mg} / \mathrm{ml}$; Invitrogen, Carlsbad, CA, USA) at $37^{\circ} \mathrm{C}$ for $40 \mathrm{~min}$. Infiltrating cells were further purified by magnetic cell sorting using CD11b-conjugate beads (Milteny Biotec, Bergisch Gladbach, Germany) and processed for RNA extraction.

Depletion of circulating phagocytes. Mice were injected intravenously with $200 \mu$ l liposomes containing Cll $(9 \mathrm{mg} / \mathrm{ml})$ or PBS (sham) 1 day before CTX injection and every 3 days afterward (after 2, 5, 8, 11, 14, 17, 20 days after CTX injection). Cll were purchased from http://www.clodronateliposomes. org/ashwindigital.asp?docid=26.

RNA extraction and quantitative real-time PCR analysis. Total RNA was extracted from TA muscles, from purified muscle-infiltrating CD11 ${ }^{+}$ cells and from FACS sorted EYFP ${ }^{+}$cells, using TRIzol reagent (Invitrogen), following the manufacturer's recommendations. Total RNA (1 $\mu \mathrm{g})$ was reverse transcribed with random hexameric primers and MultiScribe reverse transcriptase (Applied Biosystems, Warrington, UK), as described. ${ }^{22}$ cDNAs were quantified by real-time PCR on a MX 3000 apparatus (Stratagene, La Jolla, CA, USA) using specific primers (see below). PCR amplification was performed in a volume of $20 \mu \mathrm{l}$ containing $1 \mu \mathrm{l} \mathrm{cDNA}, 100 \mathrm{nmol} / \mathrm{l}$ of each primer, $4 \mathrm{mmol} / \mathrm{l} \mathrm{MgCl}$, the Brillant Quantitative PCR Core Reagent Kit mix and SYBR Green 0.333. The conditions were $95^{\circ} \mathrm{C}$ for $10 \mathrm{~min}$, followed by 40 cycles of $30 \mathrm{~s}$ at $95^{\circ} \mathrm{C}, 30 \mathrm{~s}$ at $55^{\circ} \mathrm{C}$ and $30 \mathrm{~s}$ at $72^{\circ} \mathrm{C}$. The housekeeping gene $28 \mathrm{~S}$ or cyclophilin $\mathrm{A}$ was used for normalization.

Primers sequence. Ang-I FW: 5'-AGGCTTGGTTTCTCGTCAGA-3'; Ang-I REV: 5'-TCTGCACAGTCTCGAAATGG-3'; Ang-II: FW 5'-CACAGCGAGCAGCTACAGTC-3'; Ang-II REV: 5'-ATAGCAACCGAGCTCTTGGA-3'; $\alpha$-SMA FW: $5^{\prime}$-ATTATGTTTGAGACCTTCAAT- $3^{\prime}$; $\alpha$-SMA REV: $5^{\prime}$ - GATGTCAATATCACACTTCAT-3'; BMP-2 FW: $5^{\prime}$-TCCCCAGTGACGAGTTTCTC-3'; BMP-2 REV: 5'- GTCGAAGCTCTCCCACTGAC-3'; BMP-4 FW: 5'-TGAGTACCCGGAGCGTCC-3'; BMP-4 REV: $5^{\prime}$-CTCCAGATGTTCTTCGTGATGG-3'; BMP-6 FW: 5'-ATGGCAGGACTGGATCATTGC-3'; BMP-6 REV: 5'-CCATCACAGTAGTTGGCAGCG-3'; CD31 FW: 5'-AGGGGACCAGCTGCACATTAGG-3'; CD31 REV: 5'-AGGCCGCTTCTCTTGACCACTT-3'; CD34 FW: 5'- ACCACACCAGCCATCTCAG-3'; CD34 REV: $5^{\prime}$-TAGATGGCAGGCTGGACTTC- ${ }^{\prime}$; CD45 FW: 5'-CCTGCTCCTCAAACTTCGAC- 3'; CD45 REV: 5'-GACACCTCTGTCGCCTTAGC-3'; CD90 FW 5' - GCCTGACAGCCTGCCTGGTG- 3'; CD90 REV: 5'-TGGAGAGGGTGACGCGGGAG- 3'; c/EBP FW 5'-GGCAAAGCCAAGAAGTCG-3'; c/EBP REV: 5'-TGGTCAACTCCAGCACCTT-3'; c-kit FW: $5^{\prime}$-GGCTCATAAATGGCATGCTC-3'; c-kit REV: $5^{\prime}$-TATCTCCTCGAGAACCTTCC- $3^{\prime}$; Collagen I FW: 5'-GGTATGCTTGATCTGTATCTGC-3'; Collagen I REV: 5'-AGTCCAGTTCTTCATTGCATT-3'; HIF1- $\alpha$ FW: $5^{\prime}$-TCAAGTCAGCAACGTGGAAG-3'; HIF1- $\alpha$ REV: $5^{\prime}$-TATCGAGGCTGTGTCGACTG-3'; IGF1 FW: 5' - CTCTGCTTGCTCACCTTCAC-3'; IGF1 REV 5'- CTCATCCACAATGCCTGTCT-3'; IL10 FW: 5'-ATTTGAATTCCCTGGGTGAGAAG-3'; IL10 REV: 5'-CACAGGGGAGAAATCGATGACA-3'; MMP-2 FW: $5^{\prime}$-GTCGCCCCTAAAACAGACAA-3'; MMP-2 REV: $5^{\prime}$-GGTCTCGATGGTGTTCTGGT-3'; MMP-13 FW: 5'-ATCCTGGCCACCTTCTTCTT-3'; MMP-13 REV: 5'-TTTCTCGGAGCCTGTCAACT-3'; MMP-14 FW: 5'-AGTCAGGGTCACCCACAAAG-3'; MMP-14 REV: 5'-GCATTGGGTATCCATCCATC-3'; MyoD FW: 5'-ACGGCTCTCTCTGCTCCTTT-3'; MyoD REV: 5'-GTAGGGAAGTGTGCGTGCT-3'; NG2 FW: $5^{\prime}$ - ACAAGCGTGGCAACTTTATC- $3^{\prime}$; NG2 REV 5'-ATAGACCTCTTCTTCATATTCAT-3'; Pax3 FW: 5'- TGAGTTCTATCAGCCGCATC-3'; Pax3 REV: 5'- GCCTTTTTCTCGCTTTCTTC-3'; Pax7 FW: 5'-GACTCGGCTTCCTCCATCTC-3'; Pax7 REV: 5'-AGTAGGCTTGTCCCGTTTCC-3'; PDGF- $\alpha$ FW: $5^{\prime}$-GAGATACCCCGGGAGTTGAT-3'; PDGF- $\alpha$ REV: $5^{\prime}$-TCTTGCAAACTGCAGGAATG- $3^{\prime}$; PDGF- $\beta$ FW: $5^{\prime}$-GATCTCTCGGAACCTCATCG- $3^{\prime}$; PDGF- $\beta$ REV: $5^{\prime}$-GGCTTCTTTCGCACAATCTC- $3^{\prime}$; PDGFR $\beta$ : FW $5^{\prime}$-CCGGAACAAACACACCTTCT-3'; PDGFR $\beta$ : REV $5^{\prime}$-AACATGGGCACGTAATCTATA-3'; PW1 FW: 5' - CCAAAAAGCCATCCCACA-3'; PW1 REV: 5'-TCCCTTCATAACCCCTCTCC-3'; Sca-1 FW: 5' $5^{\prime}$-TTACCCATCTGCCCTCCTAA-3'; Sca-1 REV: 5'-GGTCTGCAGGAGGACTGAGC-3'; Snail FW: $5^{\prime}$-CCACTGCAACCGTGCTTTT- $3^{\prime}$; Snail REV: $5^{\prime}$-ATGTCCTTGCTCCACAAGCAC- $3^{\prime}$; Tie2 FW: 5'-GGACAGTGCTCCAACCAAATG-3'; Tie2 REV: 5'-GACGGAAATGTTGAAAGGC-3'; TGF- $\beta$ FW: $5^{\prime}$-CCCCACTGATACGCCTGAGT-3'; TGF- $\beta$ REV: $5^{\prime}$-AGCCCTGTATTCCGTCTCCTT- $3^{\prime}$; TNF- $\alpha$ FW: $5^{\prime}$-TCCCAGGTTCTCTTCAAGGGA-3'; TNF- $\alpha$ REV: $5^{\prime}$-GGTGAGGAGCACGTAGTCGG-3'; VE-Cad: FW 5'-GTACAGCATCATGCAGGGCG-3'; 
VE-Cad REV: $5^{\prime}$-ATTCGTATCGGATAGTGGGG-3'; VEGF- $\beta$ : FW $5^{\prime}$-CCTGGAAGAACACAGCCAAT-3'; VEGF- $\beta$ REV: $5^{\prime}$-GGAGTGGGATGGATGATGTC-3'; 28S FW: 5'-AAACTCTGGTGGAGGTCCGT-3'; 28S REV: 5'-CTTACCAAAAGTGGCCCACTA-3'; Cyclophilin A FW: 5'-CATACGGGTCCTGGCATCTTGTCC-3'; Cyclophilin A REV: 5'-TGGTGATCTTCTTGCTGGTCTTGC-3'.

X-gal staining. In all, $7 \mu \mathrm{m}$ thick muscle sections were fixed with a $4 \%$ solution of paraformaldehyde (PFA) in PBS at RT, for $10 \mathrm{~min}$. Samples were then washed in PBS and incubated in X-Gal staining solution $(1 \mathrm{mg} / \mathrm{ml} 5$-bromo-4chloro-3-indolyl- $\beta$-D galactosidase, $5 \mathrm{mM} \mathrm{K4Fe}(\mathrm{CN}) 6,5 \mathrm{mM} \mathrm{K3Fe}(\mathrm{CN}) 6,2 \mathrm{mM}$ $\mathrm{MgCl} 2$ in PBS) $\mathrm{O} / \mathrm{N}$ at $37^{\circ} \mathrm{C}$. Subsequently, samples were washed, dehydrated and treated for appropriated immunostaining.

IHC and IF. Serial muscle sections were stained with hematoxylin and eosin, Masson trichrome staining (Bio-Optica, Milano, Italy), Sirius red or Oil-Red (SigmaAldrich) according to standard procedures.

IHC was performed on muscle sections fixed with $4 \%$ PFA treated with $0.3 \%$ $\mathrm{H}_{2} \mathrm{O}_{2}$ and with an avidin-biotin blocking kit (Vector Laboratories, Burlingame, $\mathrm{CA}$, USA), according to the manufacturer's instructions. Sections were blocked with $5 \%$ BSA, $0.1 \%$ Triton and $10 \%$ donkey serum in PBS for $1 \mathrm{~h}$ at RT. Subsequently, sections were incubated $\mathrm{O} / \mathrm{N}$ with primary antibody anti-CD31 $(1: 2$, clone MEC13.3, gift from E Dejana). Primary Ab was revealed using biotin-conjugated anti-rat $(1: 300) \lg$ (eBiosciences, San Diego, CA, USA) and HRP streptavidin (Vector Laboratories), and detected using Vector NovaRED substrate kit (Vector Laboratories). Specimens were counterstained with hematoxylin and examined with a Nikon Eclipse 55i microscope (Nikon, Tokyo, Japan). Parallel slides without primary $\mathrm{Ab}$ were identically processed and used as negative controls. The number and the area of CD31 + capillaries were quantified using ImageJ software $(\mathrm{NIH}$, Bethesda, MD, USA). Analysis was performed in serial transverse sections from the whole-muscle length.

For IF, muscle sections were fixed with a $4 \%$ PFA in PBS. They were permeabilized with a $0.2 \%$ Triton, $1 \%$ BSA solution in PBS for 30 min at RT and then blocked in $10 \%$ serum, $1 \%$ BSA solution in PBS for 30 min before incubation with primary antibodies: rabbit anti-mouse $\beta$-Gal (1:1500; MP Biomedicals, Illkirch, France); rabbit anti-mouse NG2 ( $1: 300$; Chemicon, Merck Millipore, Billerica, MA, USA); monoclonal anti-mouse CD31 (1:2; kind gift from E Dejana); SMA (1:200; Sigma-Aldrich); rabbit anti-mouse GFP (1:300; Invitrogen); rabbit phospho-Smad2/ 3 (Ser465/467) antibody \#3101 (1:150; Cell Signalling, Davers, MA, USA); goat anti-mouse PDGFR- $\alpha$ (1:100; R\&D Systems, Minneapolis, MN, USA); rat antimouse CD68 (1:150; AbD Serotec, Bio Rad, Hercules, CA, USA) to identify MP; rat anti-mouse CD206 (1:100; AbD Serotec), rabbit anti-mouse CD163 (1:200; Santa Cruz Biotechnology, Dallas, TX, USA) and rat anti-mouse CD86 (1:100; BD-Pharmingen, Franklin Lakes, NJ, USA) to identify different sub-population of MPs. Appropriate Alexa Fluor (Alexa 488, Alexa 594 or Alexa 546)-conjugated antibodies (1:500; Invitrogen) were used as second-step reagents. Specimens were counterstained with Hoechst 33342 (Molecular Probes, Life Technologies, Carlsbad, CA, USA) and analyzed using a Nikon microscope Eclipse E600. Image acquisition was done using the Nikon digital camera DXM1200 and the acquisition software Nikon ACT-1. Images showing double or multiple fluorescence were first acquired separately using appropriate filters, then the different layers were merged using Adobe Photoshop CS4. X-Gal staining was converted in pseudo-fluorescent colors by Adobe Photoshop.

TUNEL assay was performed on muscle sections from sham and Cll-treated mice 3 days after CTX injection using the In Situ Cell Death Detection Kit, TMR red (Roche, Basel, Switzerland), as described by the manufacturer.

Western blot. Total skeletal muscle or $\mathrm{CD}_{11 b^{+}}$infiltrating cells were lysed in $10 \mathrm{mM}$ Tris, $\mathrm{pH} 8.0,150 \mathrm{mM} \mathrm{NaCl}, 1 \%$ Nonidet P40, $0.1 \%$ sodium dodecyl sulfate (SDS), $10 \mathrm{mM}$ EDTA and protease/phosphatase inhibitors cocktail (SigmaAldrich). Lysates were centrifuged at maximum speed for $15 \mathrm{~min}$ at $4^{\circ} \mathrm{C}$. For western blot analysis, equal amounts of protein $(20 \mu \mathrm{g})$ were resolved by SDS polyacrylamide gel electrophoresis and transferred onto Immobilon-P (Merck Millipore). After Ponceau S (Sigma-Aldrich) staining, membranes were saturated in $20 \mathrm{mM}$ Tris- $\mathrm{HCl}, \mathrm{pH}$ 7.6, $150 \mathrm{mM} \mathrm{NaCl}$ (Tris-buffered saline) containing 2\% non-fat milk and $0.1 \%$ Tween 20 . Antigens were detected using the following antibodies: rabbit anti-mouse HIF1- $\alpha$ (Cayman Chemicals, Ann Arbor, MI, USA), mouse monoclonal anti-TGF- $\beta$ (clone 1D11, Bio $x$ cell, West Lebanon, NH, USA), mouse monoclonal anti- $\beta$-actin (Sigma-Aldrich), mouse monoclonal anti-GAPDH (SigmaAldrich). All antibodies were diluted in TBST $2 \%$ not-fat milk. Immunoreactive bands were revealed using an ECL detection kit (GE Healthcare Europe $\mathrm{GmbH}$, Little Chalfont, UK).

Flow cytometry. EYFP ${ }^{+}$endothelial-derived cells from Cdh5$\mathrm{CreER}^{\mathrm{T} 2}$ :R26R-EYFP mice were isolated from P11, P60 or adult mice after muscle dissection. Tissues were cut in small pieces and dissociated with $0.1 \%$ collagenase D (Roche) and $0.25 \%$ Trypsin (Gibco, Life Technology) or $0.4 \mathrm{mg} / \mathrm{ml}$ Dispase (Gibco). Dissociation reaction was performed at $37^{\circ} \mathrm{C}$ for $20 \mathrm{~min}$ for $2-3$ cycles. Resuspended mononucleated cells were filtered with 70 and $40 \mu \mathrm{M}$ filters. Cells were resuspended in either DMEM with $20 \%$ FBS, $20 \mathrm{mM}$ HEPES, $2 \mathrm{mM}$ EDTA or PBS with $2 \%$ FBS, 2 mM EDTA (for antibody staining). For FACS analyses on circulating cells, blood from tail or heart was retrieved, washed with red lysis buffer, incubated at $4{ }^{\circ} \mathrm{C}$ for $30 \mathrm{~min}$ in blocking solution (PBS with $2 \%$ FBS, 2 mM EDTA). Cell sorting was performed using the MoFLo system (DAKO, Glostrup, Denmark). FACS analysis was carried out using the BD FacsAccuri system (BD, Franklin Lakes, NJ, USA). Data were analyzed by FACSDIVA software (BD). The following antibodies were used for FACS analysis: rat anti-mouse CD45-PE (clone 30-F11, BD); rat anti-mouse CD45-PeCy7 (BD); rat anti-mouse CD31-PE (BD); unconjugated rabbit anti-mouse NG2 (Chemicon-Merck Millipore); anti-rat S/MC2.6 (kind gift from So-Ichiro Fukada) plus Streptavidine APC (BD-Pharmigen). When using unconjugated antibodies, primary antibody reaction was followed by secondary antibody donkey anti-rabbit Alexa Fluor 647.

Statistics. Differences between different experimental groups were evaluated by ANOVA analysis with Bonferroni as post hoc tests. Differences between only two experimental groups were compared by Student's $t$-test. Statistical significance was accepted for comparisons where $P<0.05$. Values presented are means \pm S.E.M.

\section{Conflict of Interest}

The authors declare no conflict of interest.

Acknowledgements. This work was supported by the European Community's framework programme FP7/2007-2013 under grants agreements n' 241440 (ENDOSTEM) (to SB and PR-Q) the Italian Ministry of Health (Fondo per gli Investimenti della Ricerca di Base-IDEAS to PR-Q and Ricerca Finalizzata to $P R-Q$ ), the Association Française contre les Myopathies (Grant 15440 to SB and PR-Q), the Italian Ministry of Research and University (PRIN 2010-11, 20108YB5W3_007 to SB).

1. Tidball JG. Inflammatory processes in muscle injury and repair. Am J Physiol Regul Integr Comp Physiol 2005; 288: R345-R353.

2. Tidball JG, Villalta SA. Regulatory interactions between muscle and the immune system during muscle regeneration. Am J Physiol Regul Integr Comp Physiol 2010; 298: R1173-R1187

3. Relaix F, Zammit PS. Satellite cells are essential for skeletal muscle regeneration: the cell on the edge returns centre stage. Development 2012; 139: 2845-2856.

4. Grenier G, Scime A, Le Grand F, Asakura A, Perez-Iratxeta C, Andrade-Navarro MA et al. Resident endothelial precursors in muscle, adipose, and dermis contribute to postnatal vasculogenesis. Stem Cells (Dayton, OH) 2007; 25: 3101-3110.

5. Dellavalle A, Maroli G, Covarello D, Azzoni E, Innocenzi A, Perani L et al. Pericytes resident in postnatal skeletal muscle differentiate into muscle fibres and generate satellite cells. Nat Commun 2011; 2: 499-11.

6. Abou-Khalil R, Le Grand F, Pallafacchina G, Valable S, Authier F-J, Rudnicki MA et al. Autocrine and paracrine angiopoietin 1/Tie-2 signaling promotes muscle satellite cell selfrenewal. Cell Stem Cell 2009; 5: 298-309.

7. Abou-Khalil R, Mounier R, Chazaud B. Regulation of myogenic stem cell behavior by vessel cells: the \&quot;ménage à trois\&quot; of satellite cells, periendothelial cells and endothelial cells. Cell Cycle (Georgetown, TX) 2010; 9: 892-896.

8. Christov C, Chretien F, Abou-Khalil R, Bassez G, Vallet G, Authier F-J et al. Muscle Satellite Cells and Endothelial Cells: close Neighbors and Privileged Partners. Mol Biol Cell 2007; 18: 1397.

9. Mantovani A, Biswas SK, Galdiero MR, Sica A, Locati M. Macrophage plasticity and polarization in tissue repair and remodelling. J Pathol 2012; 229: 176-185.

10. Corna G, Campana L, Pignatti E, Castiglioni A, Tagliafico E, Bosurgi L et al. Polarization dictates iron handling by inflammatory and alternatively activated macrophages. Haematologica 2010; 95: 1814-1822. 
11. Martinez FO, Gordon S, Locati M, Mantovani A. Transcriptional profiling of the human monocyte-to-macrophage differentiation and polarization: new molecules and patterns of gene expression. J Immunol 2006; 177: 7303-7311.

12. Mosser DM, Edwards JP. Exploring the full spectrum of macrophage activation. Nat Rev Immunol 2008; 8: 958-969.

13. Arnold L, Henry A, Poron F, Baba-Amer Y, van Rooijen N, Plonquet A et al. Inflammatory monocytes recruited after skeletal muscle injury switch into antiinflammatory macrophages to support myogenesis. J Exp Med 2007; 204: 1057-1069.

14. Bosurgi L, Corna G, Vezzoli M, Touvier T, Cossu G, Manfredi AA et al. Transplanted mesoangioblasts require macrophage IL-10 for survival in a mouse model of muscle injury. J Immunol 2012; 188: 6267-6277.

15. Lolmede K, Campana L, Vezzoli M, Bosurgi L, Tonlorenzi R, Clementi E et al. Inflammatory and alternatively activated human macrophages attract vessel-associated stem cells, relying on separate HMGB1- and MMP-9-dependent pathways. J Leukocyte Biol 2009; 85: 779-787.

16. Shireman PK. The chemokine system in arteriogenesis and hind limb ischemia. $J$ Vasc Surg 2007; 45: A48-A56.

17. Piera-Velazquez S, Li Z, Jimenez SA. Role of endothelial-mesenchymal transition (EndoMT) in the pathogenesis of fibrotic disorders. Am J Pathol 2011; 179: 1074-1080.

18. Wang Y, Nakayama M, Pitulescu ME, Schmidt TS, Bochenek ML, Sakakibara A et al. Ephrin-B2 controls VEGF-induced angiogenesis and lymphangiogenesis. Nature 2010; 465: 483-486.

19. Srinivas $S$, Watanabe T, Lin CS, William CM, Tanabe $Y$, Jessell TM et al. Cre reporter strains produced by targeted insertion of EYFP and ECFP into the ROSA26 locus. BMC Dev Biol 2001; $1: 4$.

20. Yamamoto M, Shook NA, Kanisicak O, Yamamoto S, Wosczyna MN, Camp JR et al. A multifunctional reporter mouse line for Cre- and FLP-dependent lineage analysis. Genesis (New York, NY) 2009; 47: 107-114.

21. Chen $\mathrm{X}, \mathrm{Li} \mathrm{Y}$. Role of matrix metalloproteinases in skeletal muscle: migration, differentiation, regeneration and fibrosis. Cell Adhesion Migration 2009; 3: 337-341.

22. Rigamonti E, Touvier T, Clementi E, Manfredi AA, Brunelli S, Rovere-Querini P. Requirement of inducible nitric oxide synthase for skeletal muscle regeneration after acute damage. J Immunol 2013; 190: 1767-1777.

23. Zordan P, Sciorati C, Campana L, Cottone L, Clementi E, Querini P-R et al. The nitric oxide-donor molsidomine modulates the innate inflammatory response in a mouse model of muscular dystrophy. Eur J Pharmacol 2013; 715: 296-303.

24. Li J, Qu X, Bertram JF. Endothelial-myofibroblast transition contributes to the early development of diabetic renal interstitial fibrosis in streptozotocin-induced diabetic mice. Am J Pathol 2009; 175: 1380-1388

25. Widyantoro B, Emoto N, Nakayama K, Anggrahini DW, Adiarto S, Iwasa N et al. Endothelial cell-derived endothelin-1 promotes cardiac fibrosis in diabetic hearts through stimulation of endothelial-to-mesenchymal transition. Circulation 2010; 121: 2407-2418.

26. Joe AWB, Yi L, Natarajan A, Le Grand F, So L, Wang J et al. Muscle injury activates resident fibro/adipogenic progenitors that facilitate myogenesis. Nat Cell Biol 2010; 12: 153-163.

27. Uezumi A, Fukada S-i, Yamamoto N, Takeda Sai, Tsuchida K. Mesenchymal progenitors distinct from satellite cells contribute to ectopic fat cell formation in skeletal muscle. Nat Cell Biol 2010; 12: 143-152.
28. Uezumi A, Ito T, Morikawa D, Shimizu N, Yoneda T, Segawa $M$ et al. Fibrosis and adipogenesis originate from a common mesenchymal progenitor in skeletal muscle. J Cell Sci 2011; 124: 3654-3664.

29. Maddaluno L, Rudini N, Cuttano R, Bravi L, Giampietro C, Corada M et al. EndMT contributes to the onset and progression of cerebral cavernous malformations. Nature 2013; 498: 492-496.

30. Kokudo T, Suzuki Y, Yoshimatsu Y, Yamazaki T, Watabe T, Miyazono K. Snail is required for TGFbeta-induced endothelial-mesenchymal transition of embryonic stem cell-derived endothelial cells. J Cell Sci 2008; 121(Pt 20): 3317-3324.

31. Chazaud B, Brigitte M, Yacoub-Youssef H, Arnold L, Gherardi R, Sonnet C et al. Dual and beneficial roles of macrophages during skeletal muscle regeneration. Exerc Sport Sci Rev 2009; 37: 18-22.

32. Wynn TA. Cellular and molecular mechanisms of fibrosis. J Pathol 2008; 214: 199-210.

33. Serrano AL, Muñoz-Cánoves $P$. Regulation and dysregulation of fibrosis in skeletal muscle. Exp Cell Res 2010; 316: 3050-3058.

34. Wu N, Jansen ED, Davidson JM. Comparison of mouse matrix metalloproteinase 13 expression in free-electron laser and scalpel incisions during wound healing. $J$ Investig Dermatol 2003; 121: 926-932.

35. Kaar JL, Li Y, Blair HC, Asche G, Koepsel RR, Huard J et al. Matrix metalloproteinase-1 treatment of muscle fibrosis. Acta Biomaterialia 2008; 4: 1411-1420.

36. Ohtake Y, Tojo H, Seiki M. Multifunctional roles of MT1-MMP in myofiber formation and morphostatic maintenance of skeletal muscle. J Cell Sci 2006; 119(Pt 18): 3822-3832.

37. Heredia JE, Mukundan L, Chen FM, Mueller AA, Deo RC, Locksley RM et al. Type 2 innate signals stimulate fibro/adipogenic progenitors to facilitate muscle regeneration. Cell 2013; 153: 376-388.

38. Zeisberg EM, Tarnavski O, Zeisberg M, Dorfman AL, McMullen JR, Gustafsson E et al. Endothelial-to-mesenchymal transition contributes to cardiac fibrosis. Nat Med 2007; 13 952-961.

39. Hashimoto N, Phan SH, Imaizumi K, Matsuo M, Nakashima H, Kawabe T et al. Endothelialmesenchymal transition in bleomycin-induced pulmonary fibrosis. Am J Respiratory Cell Mol Biol 2010; 43: 161-172.

40. Medici D, Shore EM, Lounev VY, Kaplan FS, Kalluri R, Olsen BR. Conversion of vascular endothelial cells into multipotent stem-like cells. Nat Med 2010; 16: 1400-1406.

41. Yang F, Chung ACK, Huang XR, Lan HY. Angiotensin II induces connective tissue growth factor and collagen i expression via transforming growth factor- -dependent and -independent Smad pathways: the role of Smad3. Hypertension 2009; 54: 877-884.

42. Wilson MS, Elnekave E, Mentink-Kane MM, Hodges MG, Pesce JT, Ramalingam TR et al IL-13Ralpha2 and IL-10 coordinately suppress airway inflammation, airway-hyperreactivity, and fibrosis in mice. J Clin Investig 2007; 117: 2941-2951.

43. Villalta SA, Rinaldi C, Deng B, Liu G, Fedor B, Tidball JG. Interleukin-10 reduces the pathology of mdx muscular dystrophy by deactivating M1 macrophages and modulating macrophage phenotype. Hum Mol Genet 2011; 20: 790-805.

(c) (i) $\odot$ Cell Death and Disease is an open-access journal published by Nature Publishing Group. This work is licensed under a Creative Commons Attribution-NonCommercialNoDerivs 3.0 Unported License. To view a copy of this license, visit http://creativecommons.org/licenses/by-nc-nd/3.0/

\section{Supplementary Information accompanies this paper on Cell Death and Disease website (http://www.nature.com/cddis)}

